\title{
Validation of Effective Models for Simulation of Thermal Stratification and Mixing Induced by Steam Injection into a Large Pool of Water
}

\author{
Hua Li, ${ }^{1}$ Walter Villanueva, ${ }^{1}$ Markku Puustinen, ${ }^{2}$ Jani Laine, ${ }^{2}$ and Pavel Kudinov ${ }^{1}$ \\ ${ }^{1}$ Division of Nuclear Power Safety, Royal Institute of Technology (KTH), Roslagstullsbacken 21, 10691 Stockholm, Sweden \\ ${ }^{2}$ Nuclear Safety Research Unit, Lappeenranta University of Technology (LUT), 53851 Lappeenranta, Finland \\ Correspondence should be addressed to Pavel Kudinov; pavel@safety.sci.kth.se
}

Received 10 January 2014; Accepted 9 July 2014; Published 16 October 2014

Academic Editor: Valerio Giusti

Copyright (c) $2014 \mathrm{Hua} \mathrm{Li}$ et al. This is an open access article distributed under the Creative Commons Attribution License, which permits unrestricted use, distribution, and reproduction in any medium, provided the original work is properly cited.

\begin{abstract}
The Effective Heat Source (EHS) and Effective Momentum Source (EMS) models have been proposed to predict the development of thermal stratification and mixing during a steam injection into a large pool of water. These effective models are implemented in GOTHIC software and validated against the POOLEX STB-20 and STB-21 tests and the PPOOLEX MIX-01 test. First, the EHS model is validated against STB-20 test which shows the development of thermal stratification. Different numerical schemes and grid resolutions have been tested. A $48 \times 114$ grid with second order scheme is sufficient to capture the vertical temperature distribution in the pool. Next, the EHS and EMS models are validated against STB-21 test. Effective momentum is estimated based on the water level oscillations in the blowdown pipe. An effective momentum selected within the experimental measurement uncertainty can reproduce the mixing details. Finally, the EHS-EMS models are validated against MIX-01 test which has improved space and time resolution of temperature measurements inside the blowdown pipe. Excellent agreement in averaged pool temperature and water level in the pool between the experiment and simulation has been achieved. The development of thermal stratification in the pool is also well captured in the simulation as well as the thermal behavior of the pool during the mixing phase.
\end{abstract}

\section{Introduction}

A pressure suppression pool (PSP) is an important element of a passive safety system in BWRs. It serves primarily as a heat sink during a loss of coolant accident (LOCA) or when the reactor is isolated from the main heat sink. The pool surface temperature defines the saturation steam pressure in the containment. Steam condensation creates a source of heat in the pool. In case of low mass flow rate of steam, weak mixing in the pool can lead to development of thermal stratification. A significant increase in temperature of the pool's top layer can result in the reduction of the pool's pressure suppression capacity which can consequently aid in the increase of containment pressure [1]. Thus a reliable prediction of mixing and stratification phenomena is necessary for safety analysis of pressure suppression pool operations.

Steam injection into a large pool of subcooled water is a source of heat and momentum. The competition between these sources defines whether the pool is thermally mixed or stratified. Previous studies relevant to modeling and simulation of suppression pool stratification and mixing phenomena can be summarized as follows.

(i) There are numerous experimental studies on stratification and mixing in a pool [2-5], but few are done in large scale tests with steam injection [6-8]. The experimental tests with steam injection have been carried out mostly with small diameter pipes mainly to clarify steam condensation regimes. In addition, not all experimental data is readily available for model development and code validation.

(ii) The use of system thermal-hydraulic 1D codes is generally unsuccessful in prediction of stratification development unless calibrated models and closures are implemented. Lumped-parameter and 1D models 


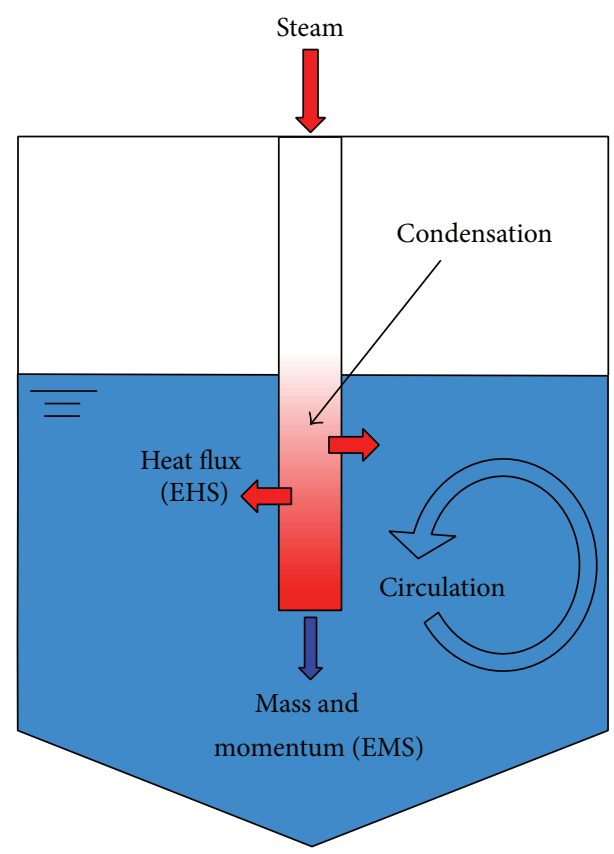

FIGURE 1: Schematic of Effective Heat Source (EHS) and Effective Momentum Source (EMS) models.

based on scaling approaches were developed and successfully used for modeling of thermal stratification development [1, 9-11]. Unfortunately, applicability of these methods is limited to stably stratified or wellmixed conditions. The time scale of erosion of a stratified layer leading to full mixing has not been addressed with these models.

(iii) The direct application of fine resolution CFD methods (e.g., RANS, LES, and DNS) in modeling 3D highRayleigh-number natural convection flows in a large pool, and, most importantly, direct contact condensation on the steam-water interface is not practical due to large uncertainty and excessive computing power.

In $[12,13]$, two effective models, namely, Effective Heat Source (EHS) and Effective Momentum Source (EMS) models, have been proposed and discussed in detail. These models can be utilized to predict thermal stratification or mixing during steam injection into a large pool of water.

The EHS model provides thermal effect of steam injection in a form of a distributed heat source. Its purpose is to conserve mass and thermal energy of injected steam. In Figure 1 schematic of the EHS model is shown. It is assumed that only hot saturated water flows out of the blowdown pipe; that is, all steam is condensed inside the blowdown pipe. Such approach correctly preserves the mass balance in the system even if some fraction of injected steam is condensed outside the pipe outlet.

The EMS model (Figure 1) provides time averaged momentum source induced by steam injection. This momentum creates large scale circulation in the pool which can lead to erosion of thermally stratified layer and mixing of the pool. Different regimes of steam condensation in the pool [15] result in different dynamics of the free surface oscillations. It was proposed $[12,13]$ to use "synthetic jet" model [16] in order to predict effective momentum generated by the oscillations of steam-water interface. Specifically, for a single harmonic oscillation, the velocity scale based on the momentum flux [17] is given as

$$
U_{0}=\sqrt{2} f L,
$$

where $f$ is the frequency of oscillation and $L$ is the amplitude of oscillation. The momentum rate is then given as

$$
M=\frac{\pi \rho U_{0}^{2} d^{2}}{4},
$$

where $\rho$ is the liquid density and $d$ is the diameter of blowdown pipe.

In the current paper, the EHS/EMS models are implemented and validated against POOLEX/PPOOLEX experiments [7, 8]. Two tests, STB-20 and STB-21, from the POOLEX series and one test, MIX-01, from the improved PPOOLEX series are used in this study. In the succeeding section, details of the implementation of EHS/EMS in GOTHIC are provided. Next, some details of the POOLEX/PPOOLEX facility are presented. Then it is followed by discussions of the validation of EHS/EMS against POOLEX/PPOOLEX experimental tests. First, validation of EHS against the POOLEX STB-20 test with development of stratification is provided and then validation of EHS/EMS against the POOLEX STB21 test with mixing of stratified layer is discussed. Lastly, validation of EHS/EMS against the PPOOLEX MIX-01 test with improved instrumentation for measurements of the oscillations in the pipe is presented and finally conclusions are given.

\section{POOLEX/PPOOLEX Experimental Facility}

A series of experiments on steam condensation, thermal stratification, and mixing in a large water pool have been performed at Lappeenranta University of Technology (Finland) with POOLEX (POOL EXperiment) and later modified PPOOLEX (Pressurized POOLEX) facility [7, 8]. The POOLEX/PPOOLEX series are among the few experiments on water pool mixing/stratification at such large scales, and the availability of data was very instrumental for the validation of EHS/EMS models [7, 8].

The POOLEX facility is an open cylindrical stainless steel tank with an outer diameter of $2.4 \mathrm{~m}$ and a water pool depth of $2.95 \mathrm{~m}$ (see Figure 2(a)). The bottom is conical and the walls are not insulated during the tests. Steam is injected through a submerged vertical blowdown pipe that has a $214 \mathrm{~mm}$ inner diameter and is located close to the center of the tank. Three vertical trains of thermocouples (with 16 thermocouples in each train) were installed in the tank to monitor water temperature during the test. Temperature inside the blowdown pipe was monitored with 3 thermocouples (TCs) with $1 \mathrm{~Hz}$ measurement frequency. These TCs can be used to estimate the level of water inside the pipe. The room temperature in the lab is also measured during the experiments since the facility is an open tank. 


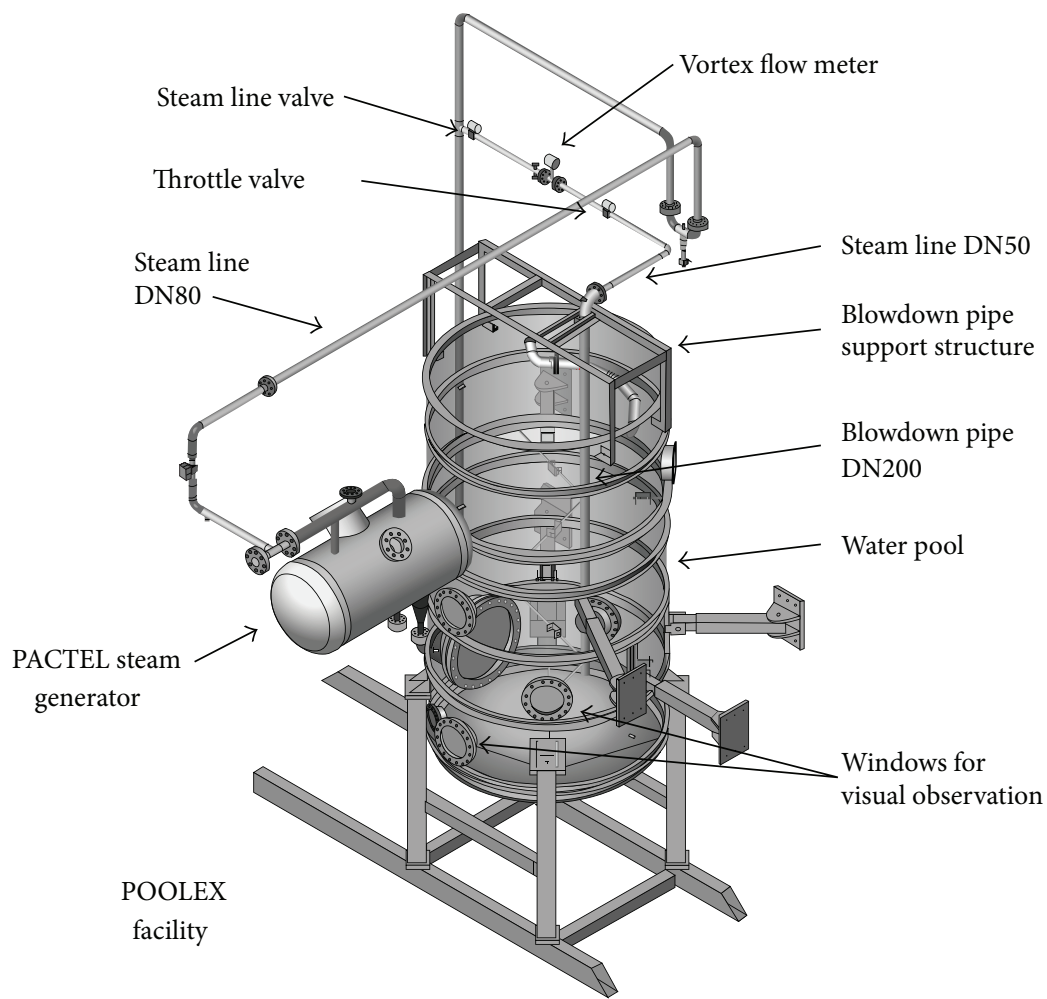

(a)

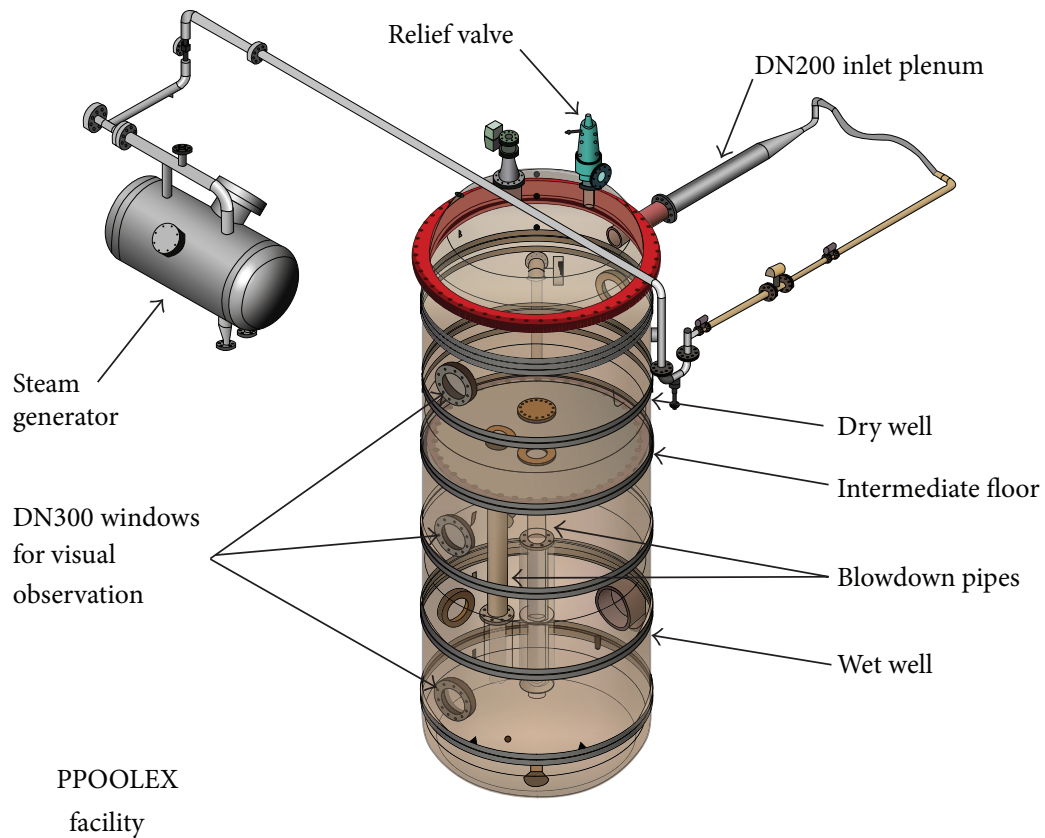

(b)

FIGURE 2: (a) POOLEX and (b) PPOOLEX experimental facility $[7,8]$.

Heating (by steam injection through the blowdown pipe) and cooling (after stop of steam injection) phases were studied in the POOLEX tests. In the STB-20 test, the steam mass flow rate was kept in the range of $25-55 \mathrm{~g} / \mathrm{s}$ to make sure that steam condenses inside the blowdown pipe. As expected during the heating phase, strong stratification above the outlet of the blowdown pipe was observed in the test, whereas the part below the pipe remained cold. In the STB-21 test, thermal stratification in the pool was formed with steam injection at a small mass flow rate similar to the STB-20 case. 


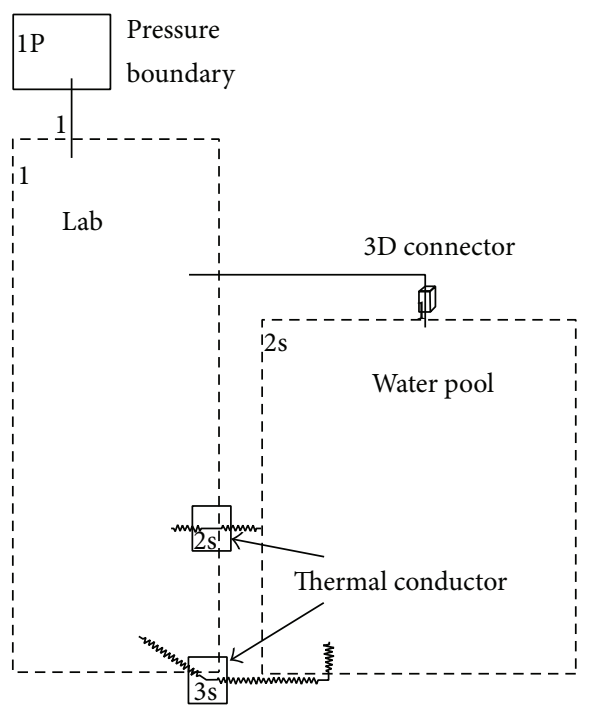

(a)

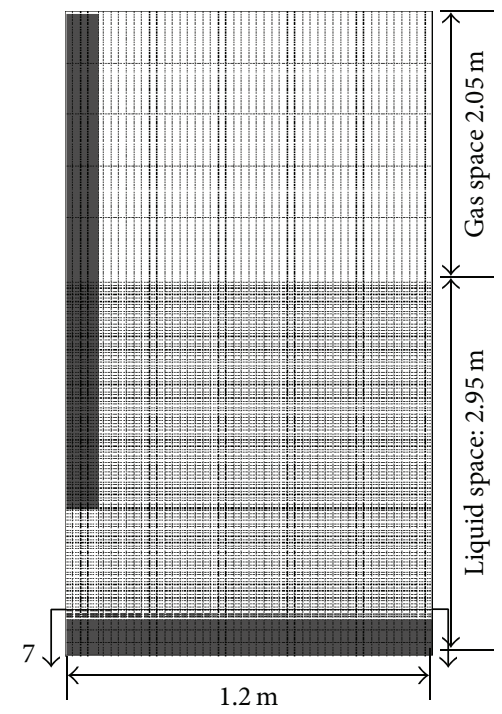

(b)

FIgURE 3: (a) EHS model scheme using GOTHIC of POOLEX STB experiment and (b) $2 \mathrm{D}$ axisymmetric mesh with $48 \times 114$ for the pool.

Then the steam mass flow rate was increased up to $210 \mathrm{~g} / \mathrm{s}$ which resulted in an erosion of the thermal stratification layers and a uniform temperature (isothermal) distribution in the pool was observed. After a period of mixing, the steam mass flow rate was decreased to the level of $35 \mathrm{~g} / \mathrm{s}$ and thermal stratification started to develop again. In both experiments the duration of the heating phase was about 4 hours while the cooling phase was about 48 hours.

The POOLEX facility was later modified to become PPOOLEX. It has both a drywell and a wetwell (see Figure 2(b)) and is considered to be realistically closer to a containment of BWRs than POOLEX. First, steam is injected through a horizontal inlet plenum and then into the drywell, and finally it discharges into the wetwell through a vertical blowdown pipe which is installed close to the central axis of the tank. A vacuum valve is installed between the drywell and the wetwell in order to balance the pressure between the compartments once the steam discharge is stopped. A series of STR and MIX tests have been performed in PPOOLEX to investigate thermal stratification and mixing. A single train of 16 TCs was installed in the wetwell at different elevations to measure the temperature distribution in the pool. In the MIX tests, a total of 17 TCs were installed inside the blowdown pipe with $20 \mathrm{~Hz}$ measurement frequency (as compared to only 3 TCs in the STB tests with $1 \mathrm{~Hz}$ measurement frequency), and the temperature readings were used to estimate the level of water inside the pipe especially during the chugging regime. The drywell wall was insulated while the wetwell was not insulated. In the MIX-01 test, there was a clearing phase which took about $500 \mathrm{~s}$ followed by development of thermal stratification for about $2200 \mathrm{~s}$. An increase in steam mass flow rate resulted in thermal mixing that took about $300 \mathrm{~s}$. The pool remained thermally mixed until the end of the test.

\section{Validation of Effective Heat Source (EHS) Model against POOLEX STB-20 Test}

3.1. GOTHIC Modeling and Assumptions. In the POOLEX STB-20 test [7], practically all steam condenses inside the blowdown pipe and the steam-water interface stays close to the pipe outlet. And since the mass flow rate in the STB-20 test is considered small, it is then assumed that the momentum induced by the condensate flowing out of the pipe outlet is negligible. In addition, the mass added into the pool due to steam injection is neglected in the modeling since the water inventory in the pool has only increased about $4 \%$ during the entire heating phase. Thus, the EHS model is only used to simulate STB-20 while both EHS and EMS models are used in STB-21 since the effective momentum there is significant.

The EHS model scheme using GOTHIC 8.0 for the POOLEX STB-20 test is shown in Figure 3(a). A large size lumped volume (marked "1") corresponds to the lab which models the lab's temperature with a ventilation system. In addition, this lumped volume 1 is connected to a pressure boundary (marked "1P") to keep the pressure constant in the lab. One 3D connector models the connection between the gas space of the fully-open water tank and the lab. The heat losses through the side wall and bottom of the water tank are modeled by two thermal conductors, " $2 \mathrm{~s}$ " and " $3 \mathrm{~s}$," respectively. The GOTHIC built-in heat transfer models are chosen for the thermal conductors.

The water tank is modeled as a $2 \mathrm{D}$ axisymmetric volume (Volume " $2 \mathrm{~s}$ "). GOTHIC supports only Cartesian coordinate system so, in order to make a cylindrical geometry for volume $2 \mathrm{~s}$, the porosities of volume and surface area of all cells are adjusted. The spaces occupied by pipe and bottom conical section are modeled by blockage and with assumption that the bottom is flat. It is also assumed that the blowdown pipe is 
located at the center of the tank as opposed to a $0.3 \mathrm{~m}$ distance between the center and the pipe.

The injection of steam is not modeled in GOTHIC. Instead, the effect of steam blowdown is modeled by the Effective Heat Source (EHS) model which is equal to the heat brought by condensing steam and is distributed uniformly on the surface of the blowdown pipe. The heat flux is imposed by an internal thermal conductor which is spanned along the pipe side surface from the water level to the pipe outlet level and placed inside the cells adjacent to the submerged pipe blockage not including the bottom.

There are 3 mesh grids used for the water tank to determine the influence of grid resolution. The coarsest grid has 12 cells in the horizontal direction and a total of 34 cells in the vertical direction, that is, 29 cells in the liquid part, 1 cell for the liquid-gas interface, and 4 cells in the gas space. The mesh cell sizes are $0.1 \mathrm{~m} \times 0.1 \mathrm{~m}$ for the liquid part, $0.5 \mathrm{~m} \times 0.1 \mathrm{~m}$ for the cell with the liquid-gas interface, and $0.4 \mathrm{~m} \times 0.1 \mathrm{~m}$ for the gas space of the tank. The middle grid has 24 cells in the horizontal direction and a total of 60 cells in the vertical direction with distribution of cells similar to the coarsest grid except for adding 26 cells to the liquid part. The finest grid has 48 cells in the horizontal direction and a total of 114 cells in the vertical direction with distribution of cells similar to the coarsest grid except for adding 80 cells to the liquid part, as shown in Figure 3(b).

The standard k-e turbulence model is used. A second order difference scheme for spatial integration and first order semi-implicit scheme for time integration are chosen in GOTHIC. An adaptive time-step option is implemented with minimum and maximum time-steps of $10^{-4} \mathrm{~s}$ and $1 \mathrm{~s}$, respectively.

3.2. Analysis of Results. The comparison between experimental and predicted liquid average temperature is shown in Figure 4. In the STB-20 test, the initial temperature is around $30^{\circ} \mathrm{C}$ and increases up to $52.4^{\circ} \mathrm{C}$ during the heating phase. All the simulations predicted the average temperature excellently especially during the first half of the heating phase. The coarsest grid has a difference of only about $1^{\circ} \mathrm{C}$ near the end of the heating phase of the experiment while the finer grids have even smaller difference against the experiment. It can be fairly stated here that the heat balance during the heating phase is not sensitive to grid resolution.

Figure 5 shows the snapshot of temperature profiles in the pool with the EHS model using 3 different grids, $12 \times 34$, $24 \times 60$, and $48 \times 114$ cells, at $t=14000 \mathrm{~s}$ compared against STB-20 experimental data. As expected all the simulation cases predicted the cold bottom layer $\left(30^{\circ} \mathrm{C}\right)$ in the experiment since no effective momentum has been imposed in the modeling. High gradient in temperature is observed in the vicinity of the level of the pipe outlet which is captured by the simulations. Then the temperature increases more slowly to about $66^{\circ} \mathrm{C}$ in the experiments than in the simulations. The finest grid captures better the temperature of the upper layer with the maximum temperature at the top at about $65^{\circ} \mathrm{C}$ compared to about $64^{\circ} \mathrm{C}$ with the coarser grids.

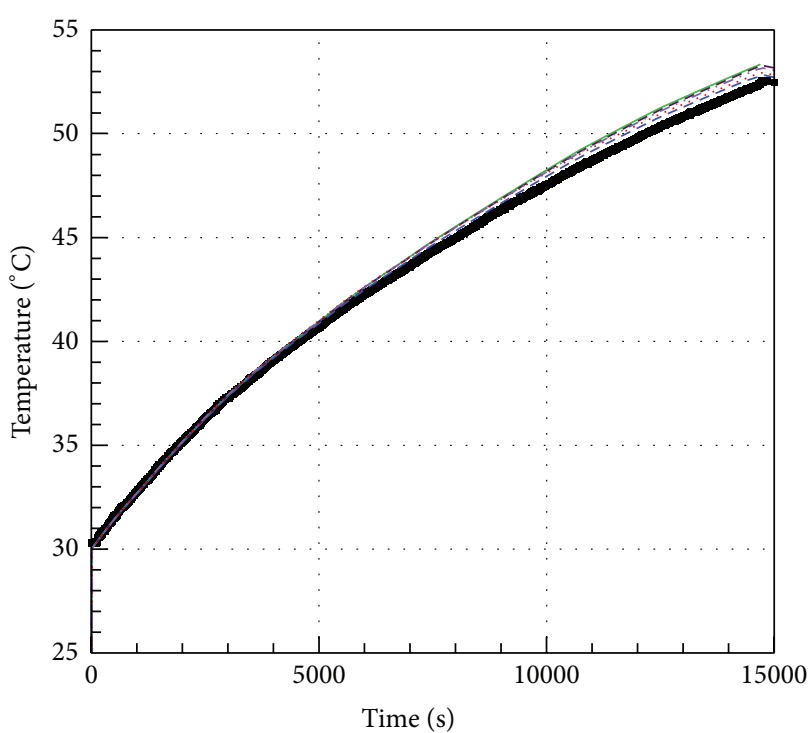

$$
\begin{aligned}
& \text { - STB-20 test - - - EHS with } 24 \times 60 \text { FOUP } \\
& \text { — EHS with } 12 \times 34 \quad \ldots \ldots \text { EHS with } 48 \times 114 \text { BSOUP } \\
& \text { - - - EHS with } 24 \times 60 \text { BSOUP … . EHS with } 48 \times 114 \text { FOUP }
\end{aligned}
$$

Figure 4: Average liquid temperature calculated with different grid resolution compared to STB-20 experimental data. The acronyms "BSOUP" and "FOUP" stand for "Bounded Second-Order Upwind" and "First-Order Upwind" schemes, respectively.

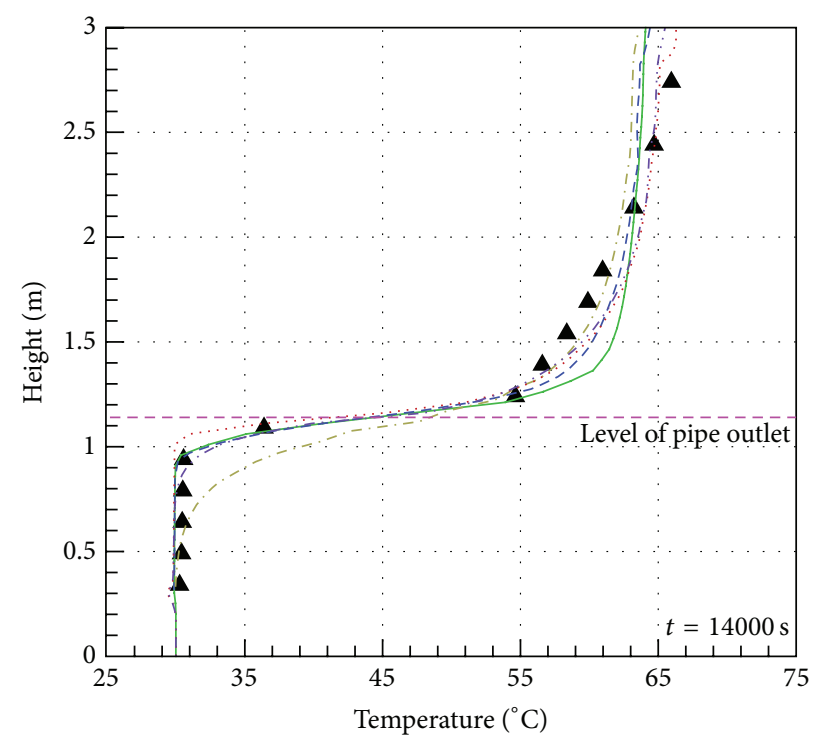

$$
\begin{aligned}
& \text {. STB-20 test _.... EHS with } 24 \times 60 \text { FOUP } \\
& \text { _ EHS with } 12 \times 34 \quad \ldots . . \text { EHS with } 48 \times 114 \text { BSOUP }
\end{aligned}
$$

FIGURE 5: Snapshot of temperature profiles predicted by EHS using different grids from a radius of $0.6 \mathrm{~m}$ from the center (midline) as a function of height at time $t=14000 \mathrm{~s}$ in comparison with STB20 experimental data. The acronyms "BSOUP" and "FOUP" stand for "Bounded Second-Order Upwind" and "First-Order Upwind" schemes, respectively. 


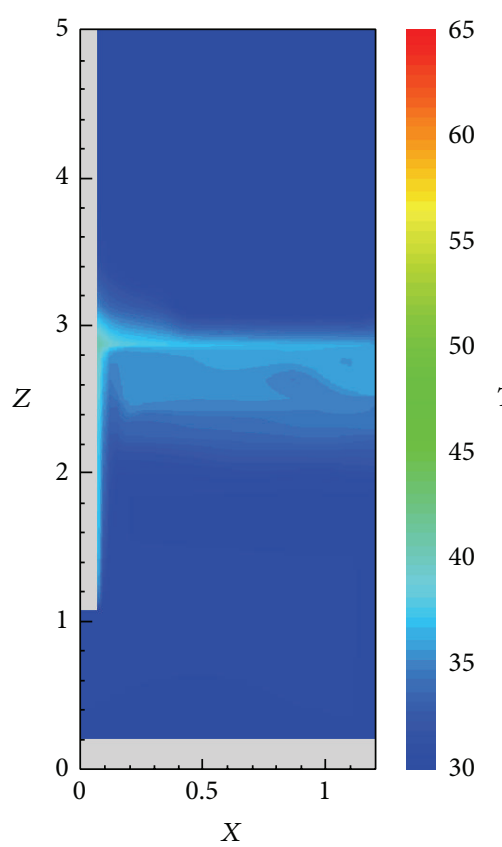

(a) $t=500 \mathrm{~s}$

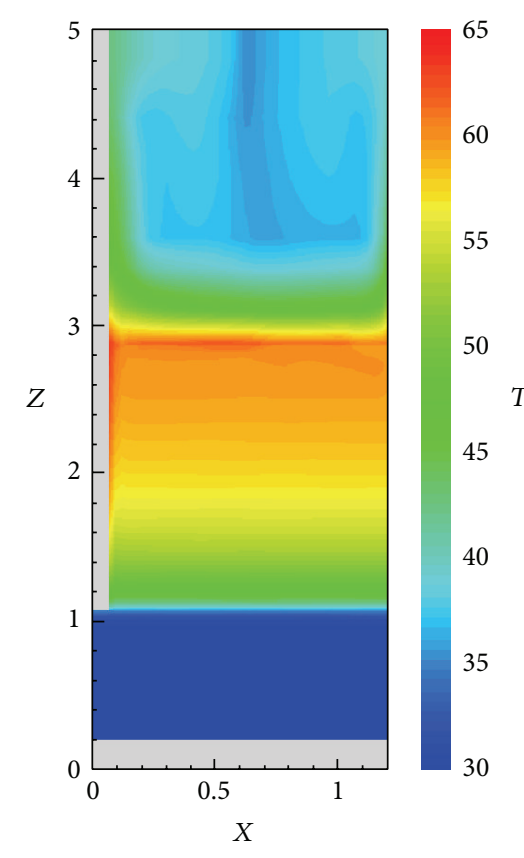

(b) $t=10000 \mathrm{~s}$

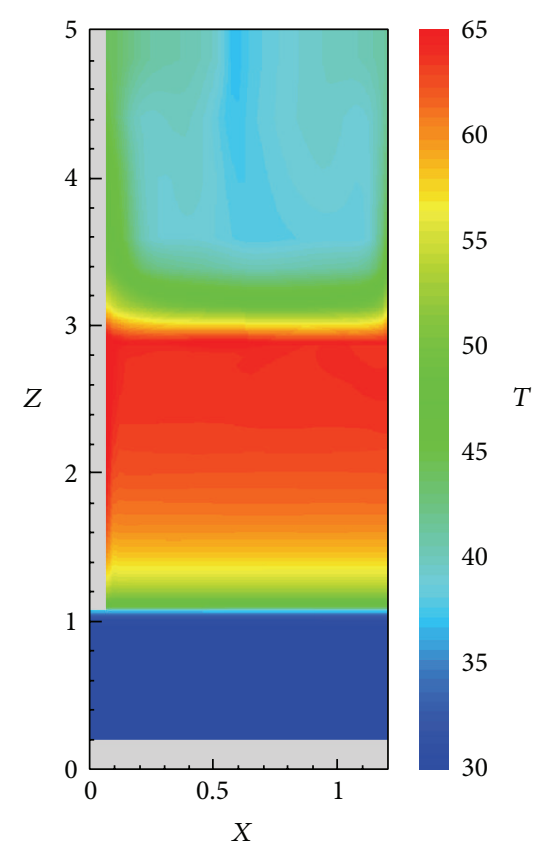

(c) $t=13000 \mathrm{~s}$

FIGURE 6: Temperature distribution at different times $t=500,10000$, and $13000 \mathrm{~s}$ with EHS simulation of STB-20 test using $48 \times 114$ cells.

EHS simulation results showing the temperature distribution in the tank at different times $t=500,10000$, and $13000 \mathrm{~s}$ can be seen in Figure 6. In Figure 6(a) at $500 \mathrm{~s}$, the heat source starts to heat up the water surrounding the blowdown pipe creating a buoyant plume that goes upward and circulates and also heats up part of the gas space. At a later time $t=10000 \mathrm{~s}$ (Figure 6(b)), the bottom layer remains cold and heating of the upper layer including the gas space intensifies with maximum temperature reaching about $62^{\circ} \mathrm{C}$. Further at $t$ $=13000 \mathrm{~s}$ (Figure 6(c)), the build-up of thermal stratification layers is more pronounced and the maximum temperature even increases to about $70^{\circ} \mathrm{C}$.

The calculation time for the $14700 \mathrm{~s}$ transient took about $\sim 10$ min with $12 \times 34$ cells on 1 core in an i5 $3.2 \mathrm{GHz}$ desktop with BSOUP and direct pressure solution while it took about $\sim 2 \mathrm{~h}$ with $24 \times 60$ cells on the same desktop and the same numerical methods. For the $48 \times 114$ cells with BSOUP, it took about $\sim 14 \mathrm{~h}$ on 4 cores in an i7 $3.4 \mathrm{GHz}$ desktop with conjugate gradient method.

\section{Validation of EHS and EMS (Effective Momentum Source) Models against POOLEX STB-21 Test}

An important criterion in the erosion of a thermally stratified pool by steam injection is the time needed to reach an isothermal pool. Not surprisingly, this time scale of mixing is also important in the operation of pressure suppression pools. Thus, predictive capabilities of proposed models should be assessed not only for averaged temperatures and thermal behaviour of certain layers but also for the time scale of mixing.
Figure 7(a) shows the vertical temperature distribution measured in the test STB-21 of POOLEX experiment while Figure 7 (b) shows the corresponding steam flow rate from the steam generator. The general behavior of the STB-21 test can be divided into 6 phases. In phase A, mixing is observed before $1800 \mathrm{~s}$ (line 0 in Figure 7(a)). At $1800 \mathrm{~s}$ of phase B, thermal stratification begins to develop in the layer above the pipe outlet. In phase $C$ at 3250 s (line 1), the temperature of the layer below the pipe remains steady at a constant value. In phase D at about $4200 \mathrm{~s}$ (line 2), the injected steam flow rate has been rapidly increased to about $210 \mathrm{~g} / \mathrm{s}$. Complete mixing is achieved around $4900 \mathrm{~s}$ when the pool is considered isothermal around $41^{\circ} \mathrm{C}$. The pool remains isothermal with increasing averaged temperature in phase $\mathrm{E}$ and finally in phase $\mathrm{F}$ the pool starts to develop thermal stratification again. For the validation of EHS/EMS models, we consider the build-up of thermal stratification (phase C) and mixing (phase D).

Figure 7(c) shows part of the data simulated with EHSEMS models while Figure 7(d) shows the corresponding heat rates used in the EHS implementation. The main reason behind this heat flux that changes from imposing it on the pipe's submerged surface to the pipe's exit is the limited wall condensation at high steam flow rates and most of the energy release is expected at the pipe's exit where direct contact condensation occurs. In the succeeding section, we also investigate the effect of heat flux distribution on the case with uniform heat fluxes on the pipe's submerged surface.

4.1. Estimation of Effective Momentum. The effective momentum can be calculated based on the synthetic jet theory which relates the thrust velocity to the frequency and amplitude 

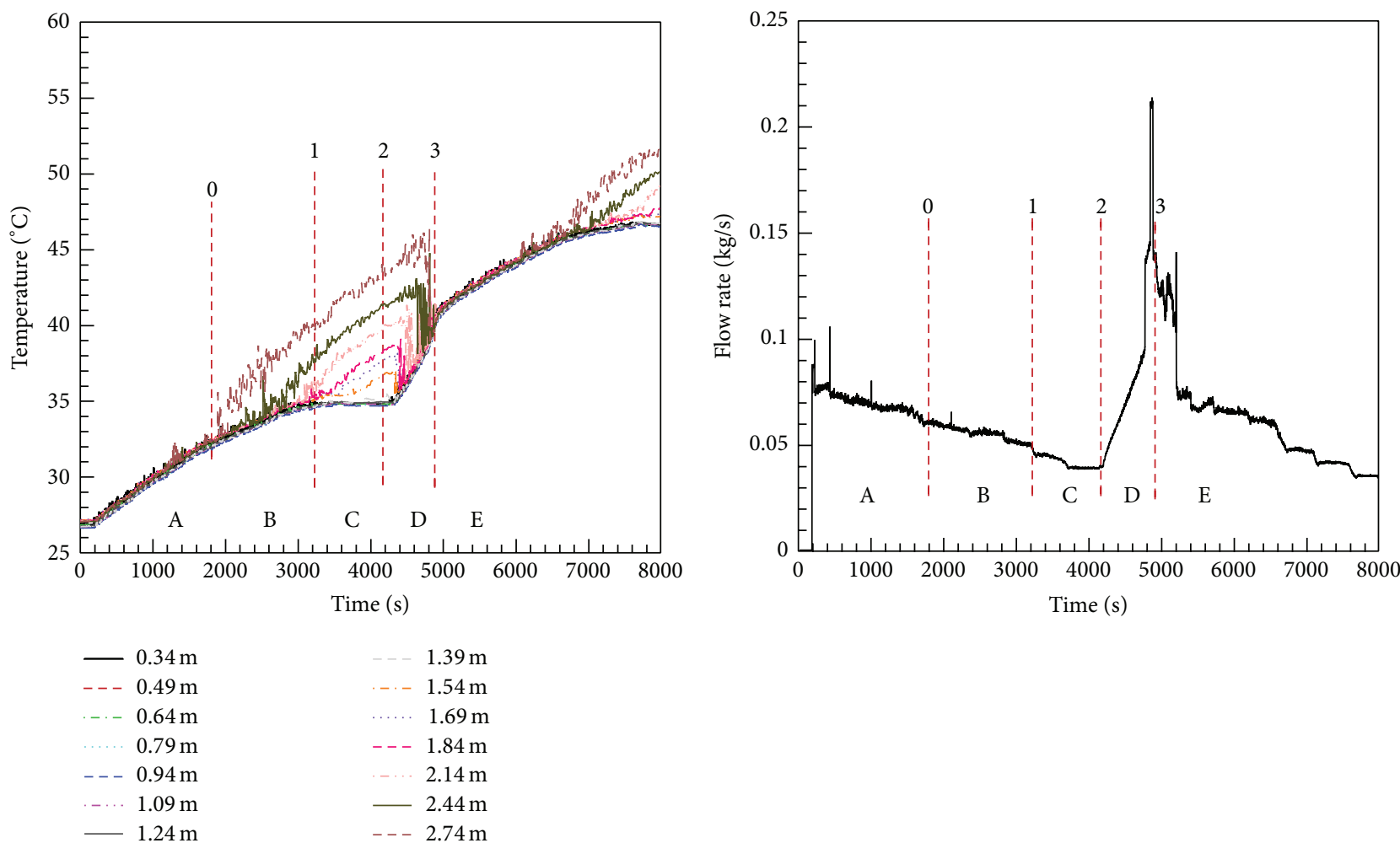

(a)

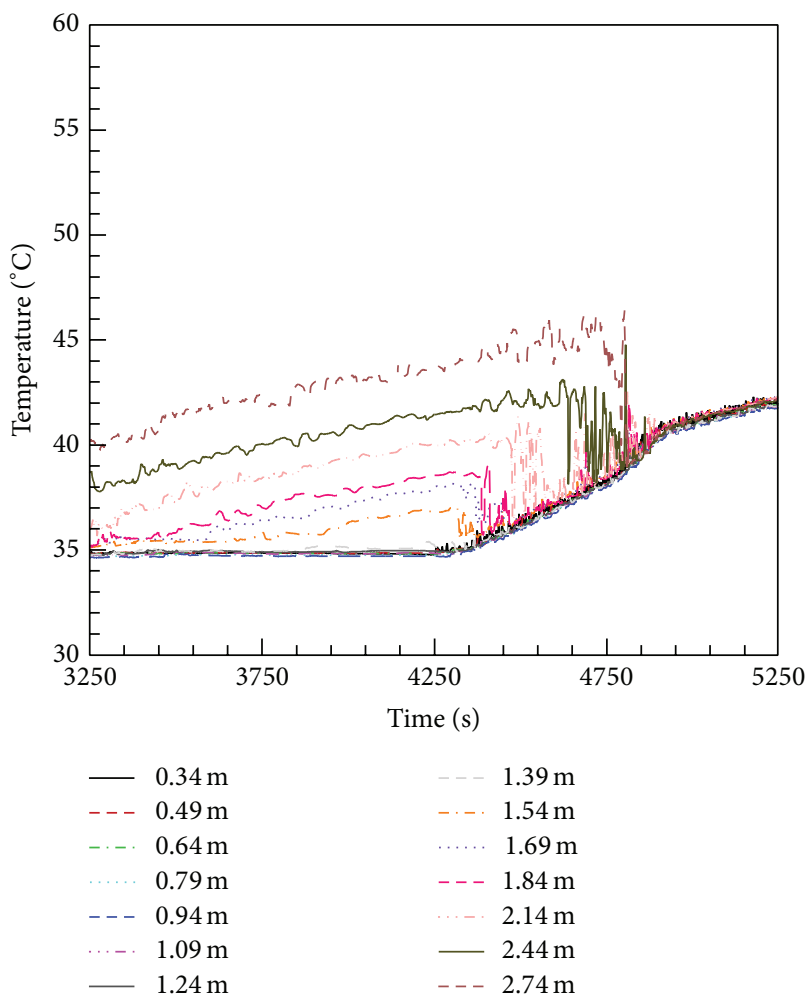

(b)

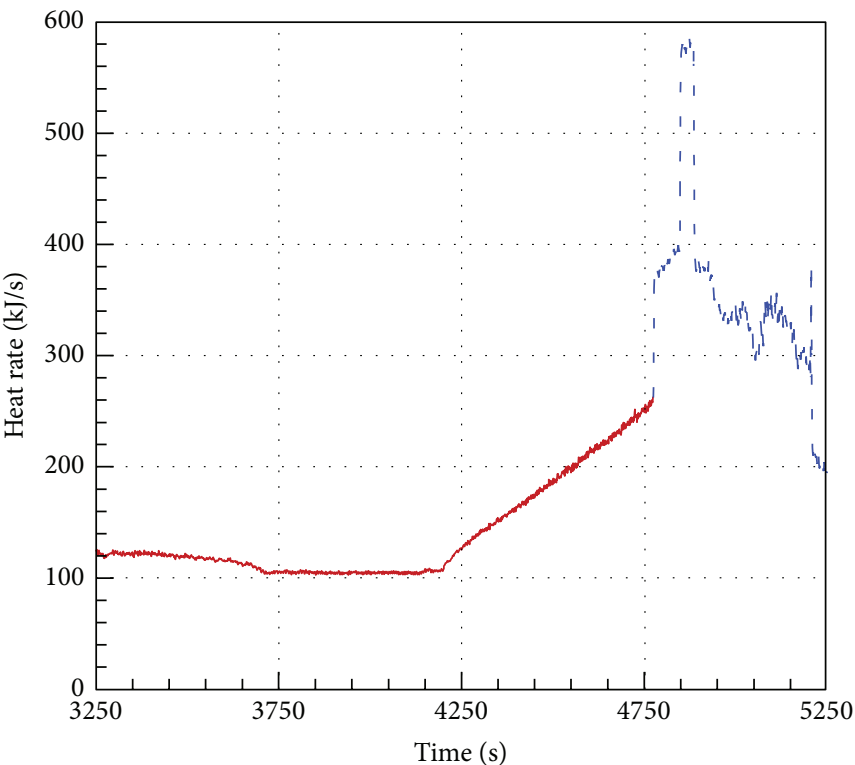

- On the pipe's surface At the pipe's exit

(c)

(d)

FIGURE 7: (a) Vertical temperature distribution in STB-21 test, (b) measured steam flow rate, (c) part of data simulated with EHS-EMS models, and $(\mathrm{d})$ corresponding imposed heat fluxes that change from the pipe's submerged surface to the pipe's exit. Phase A: first mixing. Phase B: onset of stratification. Phase C: stratification. Phase D: onset of second mixing. Phase E: second mixing followed by stratification. 


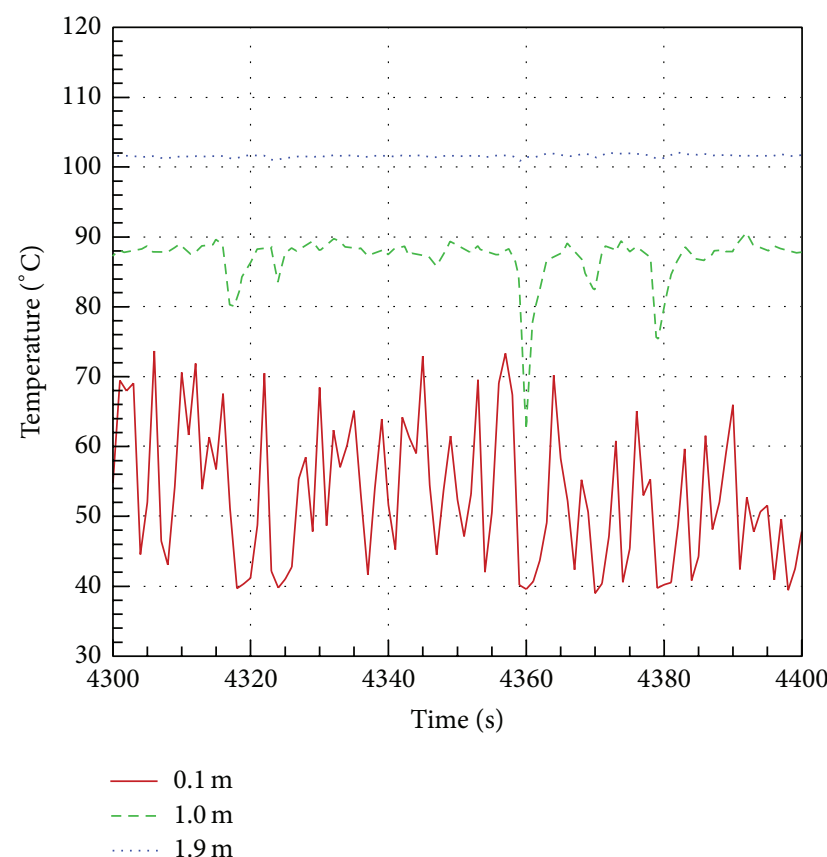

(a)

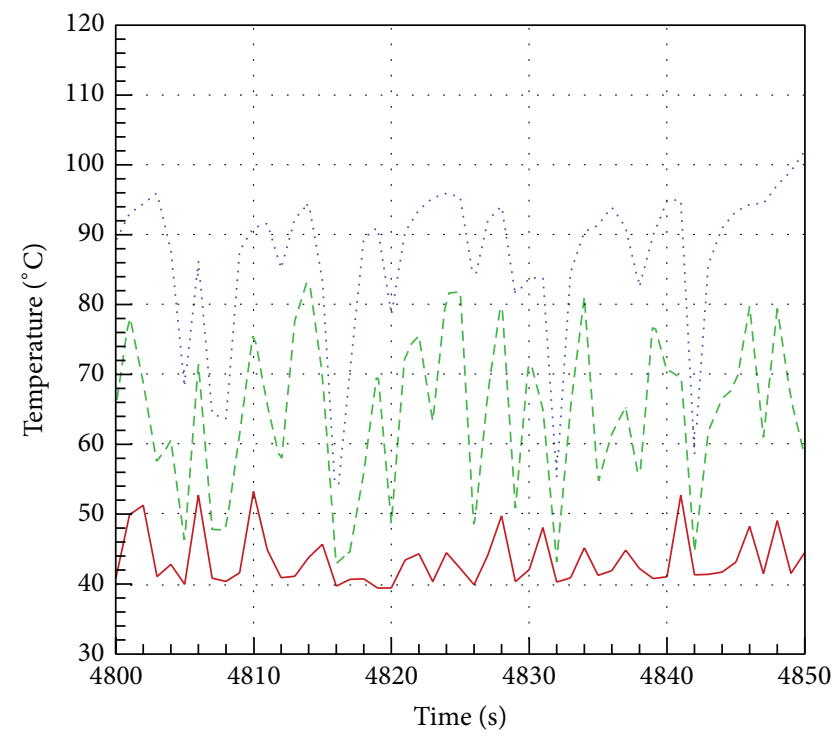

$\begin{array}{rr}- & 0.1 \mathrm{~m} \\ --- & 1.0 \mathrm{~m} \\ \ldots . . & 1.9 \mathrm{~m}\end{array}$

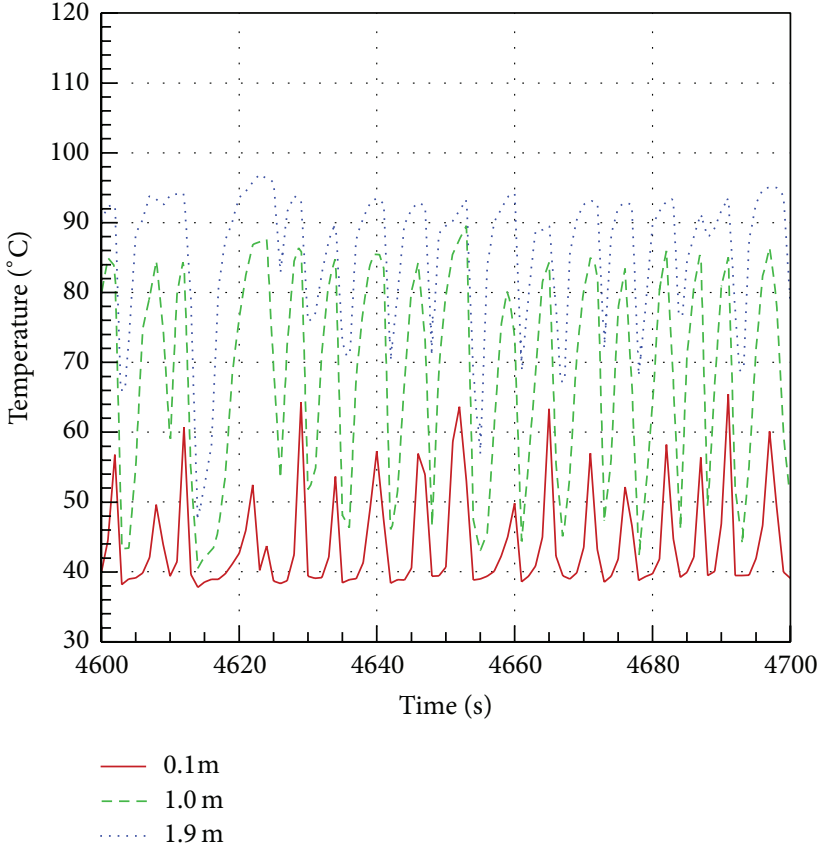

(b)

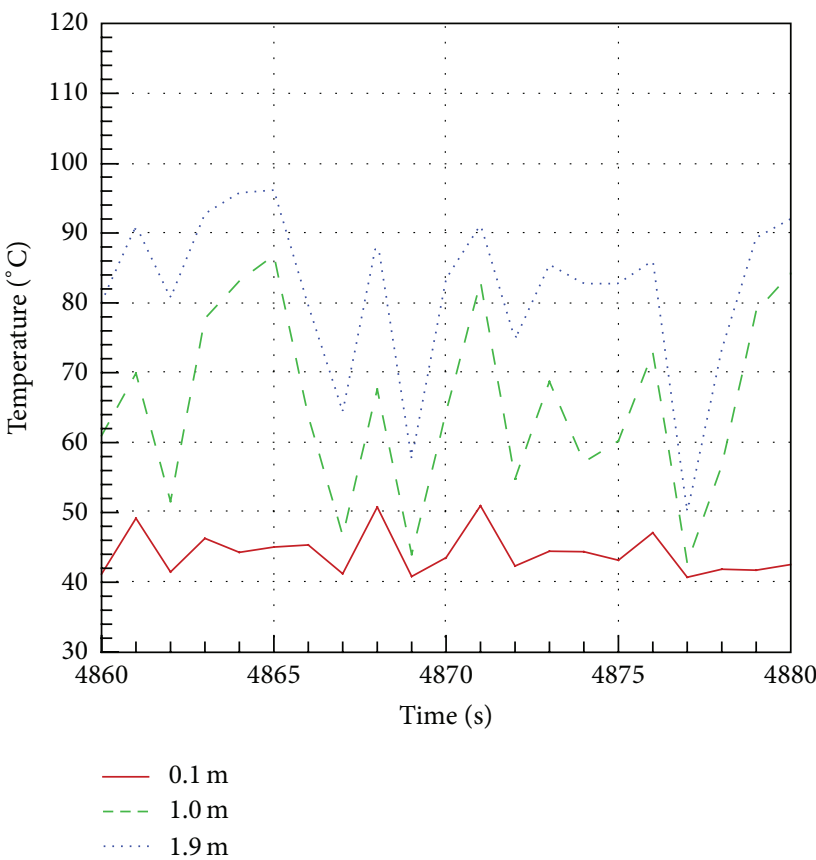

(d)

FIGURE 8: Thermocouple measurements inside the blowdown pipe during STB-21 test at representative time periods taken with 3 TCs at $0.1 \mathrm{~m}$, $1.0 \mathrm{~m}$, and $1.9 \mathrm{~m}$ distances from the pipe outlet.

of water-level oscillation inside the blowdown pipe (see [12, 13] for more details). In the POOLEX facility, only three thermocouples are installed inside the blowdown pipe which can be used to determine the water level during a test.

Figure 8 shows thermocouple measurements inside the blowdown pipe in the STB-21 test at representative time periods. The oscillation patterns are different in each time period due to varying pool temperature and steam mass flow rates. In Figure 8(a), TC measurements between $4300 \mathrm{~s}$ and $4400 \mathrm{~s}$ are shown where changes happen mostly at the $0.1 \mathrm{~m}$ level which makes the estimation of amplitude and frequency of water level oscillation highly uncertain. However, it can be discerned from the figure that the water level (with obviously the water having much lower temperature than 


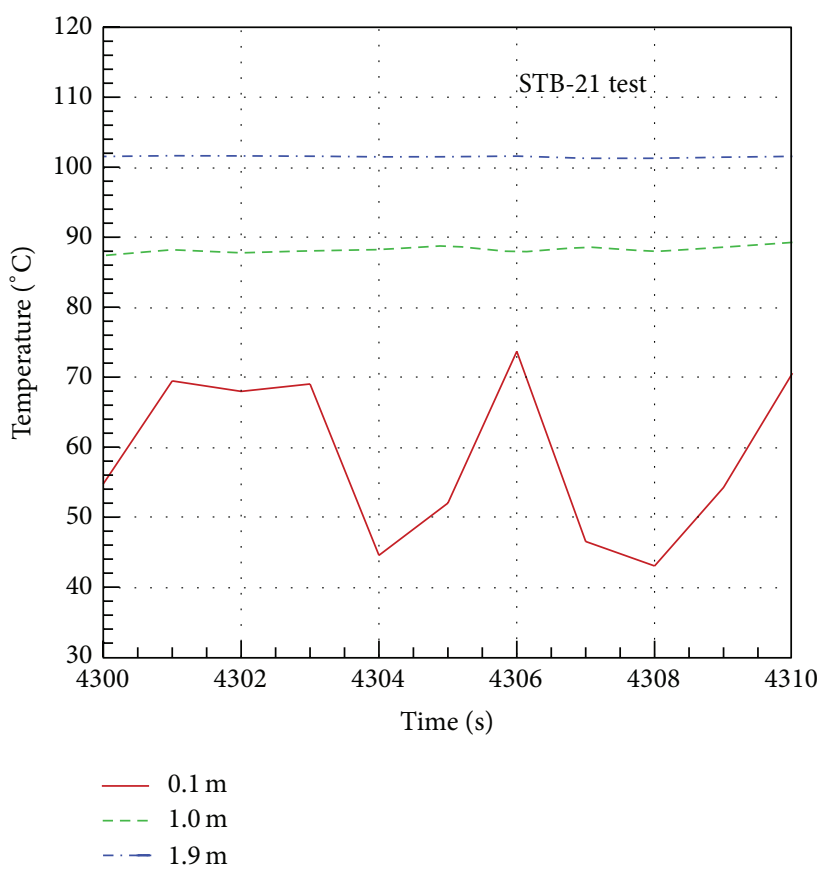

(a)

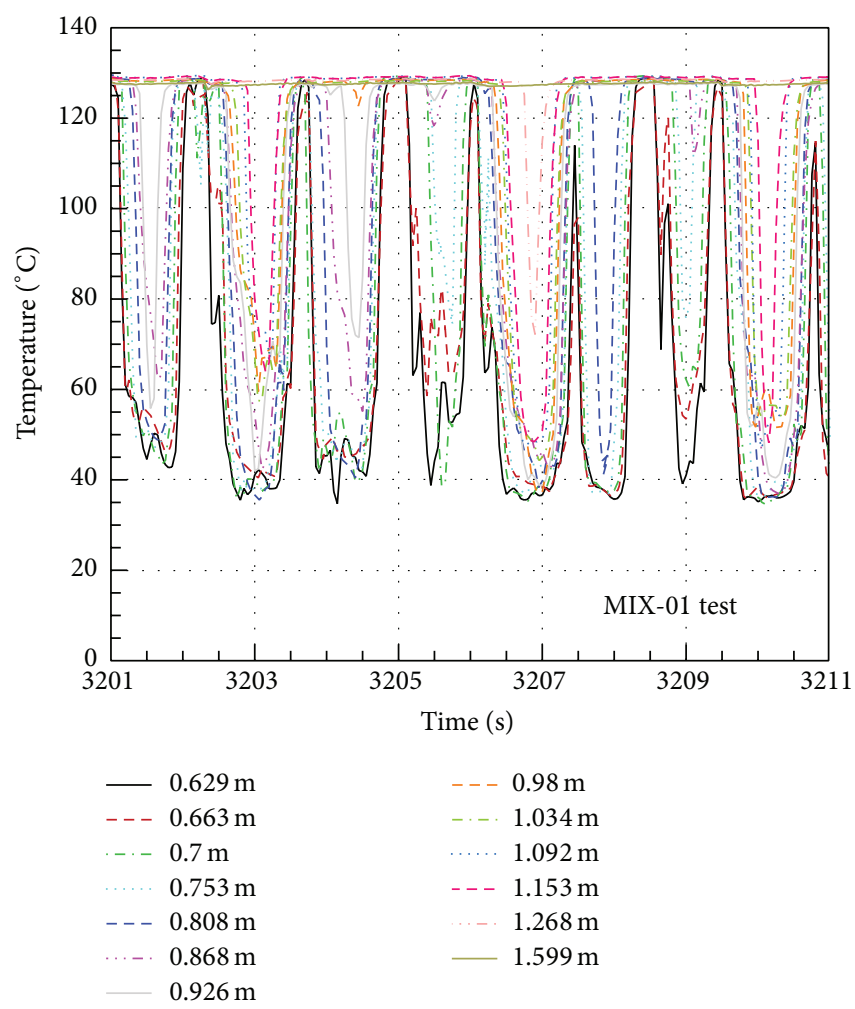

(b)

FIGURE 9: Improvement in space and time resolution of temperature measurements inside the blowdown pipe during the chugging regime in MIX-01 test as compared to STB-21 test.

the steam) is oscillating inside the blowdown pipe. Roughly, the amplitude and frequency of oscillation are estimated to be between $0.3-0.4 \mathrm{~Hz}$ and $0.1-1.0 \mathrm{~m}$, respectively. Clearly, more thermocouples installed inside the blowdown pipe are necessary in order to provide more accurate assessment of the amplitude and frequency of oscillation. Such improvement is implemented in the PPOOLEX MIX-01 test and an example is shown in Figure 9.

In Figure 8(b), TC measurements from time $t=4600 \mathrm{~s}$ to $t=4700 \mathrm{~s}$ are shown. Temperature at the $1.9 \mathrm{~m}$ level also reaches lower temperature implying that the water level oscillates with peaks reaching that level. In addition, the frequency is lower in this time period than in the previous period and is roughly estimated to be between 0.18 and $0.25 \mathrm{~Hz}$ while the amplitude is estimated to be between 1.0 and $1.9 \mathrm{~m}$. Similarly, frequency and amplitude of oscillations have been estimated for the time periods 4800-4850 s (Figure 8(c)) and 4860$4880 \mathrm{~s}$ (Figure $8(\mathrm{~d})$ ) and summarized in Table 1 . Given the frequency $f$ and amplitude $L$ of water level oscillation in the blowdown pipe, we can calculate the effective momentum based on the synthetic jet (see (1), (2)). Due to uncertainty in the estimated values from TC measurements, different cases were parametrically studied (to be discussed in the next section). They correspond to the minimum, maximum, and somewhere in-between values and are also summarized in Table 1 .
4.2. EHS-EMS Models Validation and Parametric Studies. As mentioned in the previous section, different momentum rates are chosen as momentum sources for the validation of EMS against the STB-21 test. In the GOTHIC implementation, a pump component is used to impose the effective momentum rates with actual input values of volumetric flow rates as shown in Figure 10 for the cases. Ideally, a component (momentum source) could be created in a tool like GOTHIC which can be used to impose effective momentum given the steam mass flux, pipe diameter, and pool bulk temperature.

Figure 11 shows the comparison of different cases of EHS/EMS simulations against the STB-21 test (see Figure $7(\mathrm{c})$ ). Case 1 (Figure 11(a)) corresponds to the minimum momentum rate with uniform heat flux on the pipe's submerged surface. Case 2a (Figure 11(b)) corresponds to a chosen momentum rate between the minimum and maximum values (as shown in Table 1) with also uniform heat flux on the pipe's submerged surface. Case $2 b$ (Figure 11(c)) is the same as Case 2a except that the heat flux shifts from the pipe's submerged surface to the pipe's exit (as shown in Figure $7(\mathrm{~d})$ ). Lastly, Case 3 (Figure 11(d)) corresponds to the maximum momentum rate with uniform heat flux as in the other cases.

In Case 1, a build-up of thermal stratification is also observed similar to the stratification phase in the experiment but in this case the stratification prolongs for another $500 \mathrm{~s}$ 
TABLE 1: Estimation of effective momentum given the frequency and amplitude of water level oscillations inside the blowdown pipe in STB-21 test.

\begin{tabular}{|c|c|c|c|c|c|c|c|}
\hline \multicolumn{4}{|c|}{$\begin{array}{l}\text { Estimated frequency and amplitude of oscillations based on TC } \\
\text { measurements in STB- } 21\end{array}$} & \multicolumn{4}{|c|}{$\begin{array}{l}\text { Velocity based on synthetic jet theory and chosen momentum } \\
\text { rates within the estimated range of velocity }\end{array}$} \\
\hline \multirow{2}{*}{$\begin{array}{l}\text { Time } \\
{[\mathrm{s}]}\end{array}$} & \multirow{2}{*}{$\begin{array}{l}\text { Period } \\
{[s]}\end{array}$} & \multirow{2}{*}{$\begin{array}{l}\text { Frequency } \\
{[\mathrm{Hz}]}\end{array}$} & \multirow{2}{*}{$\begin{array}{l}\text { Amplitude } \\
{[\mathrm{m}]}\end{array}$} & \multirow{2}{*}{$\begin{array}{l}\text { Velocity } \\
{[\mathrm{m} / \mathrm{s}]}\end{array}$} & \multicolumn{3}{|c|}{ Momentum rate $\left[\mathrm{kg} \cdot \mathrm{m} / \mathrm{s}^{2}\right]$} \\
\hline & & & & & Case 1 & Cases 2(a) and 2(b) & Case 3 \\
\hline $4300-4400$ & $2.5-3.3$ & $0.303-0.4$ & $0.1-1.0$ & $0.043-0.57$ & 0.066 & 10.32 & 11.5 \\
\hline $4600-4700$ & $4-5.6$ & $0.18-0.25$ & $1.9-3.8$ & $0.48-1.36$ & 8.43 & 54.4 & 67 \\
\hline $4800-4850$ & $2.5-3.3$ & $0.3-0.4$ & $1.9-3.8$ & $0.81-2.18$ & 23.4 & 151 & 171.5 \\
\hline $4860-4880$ & $2-3.1$ & $0.33-0.5$ & $1.9-3.8$ & $0.88-2.73$ & 27.55 & 177.7 & 268 \\
\hline
\end{tabular}

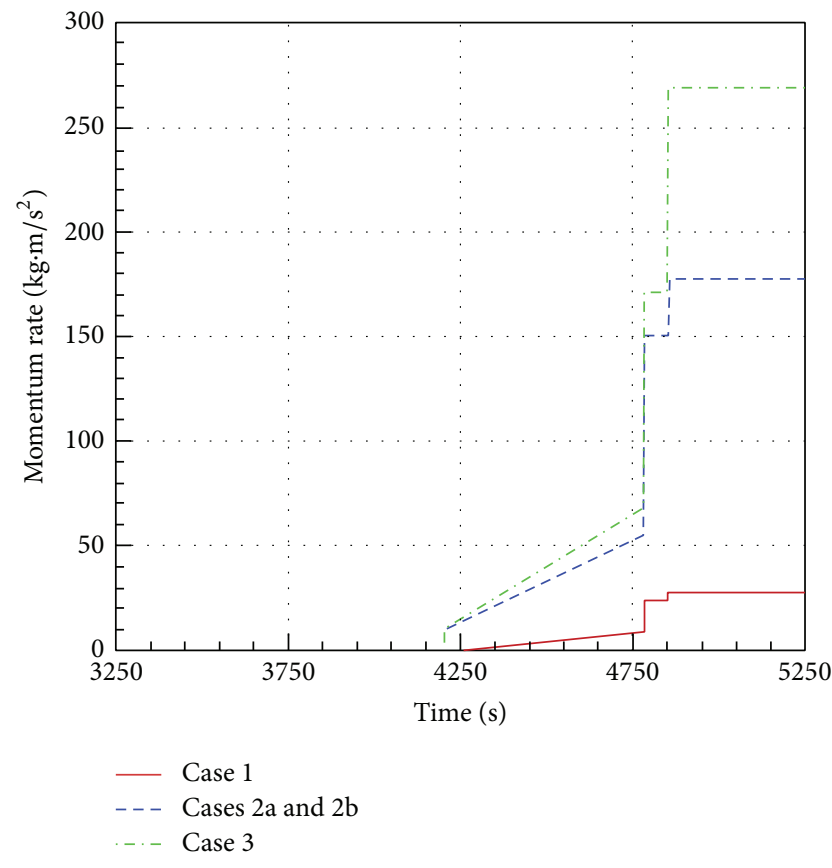

FIGURE 10: Input volumetric flow rates for the pump corresponding to different effective momentum rates as shown in Table 1.

and the upper layer remains stratified with increasing temperature until the end. In Case $2 \mathrm{a}$, a similar behavior to Case 1 is observed with the main difference of having a thinner layer at the top that remains stratified with increasing temperature. In these two cases, the temperature at the top layer increases significantly and does not mix with the pool which means that the heat source dominates over the momentum source. In Case 2b, however, when the heat flux at high flow rates is shifted from the pipe's submerged surface to the pipe's exit (where most heat releases occur due to significant contact condensation), the clockwise flow circulation in the pool due to buoyant plume directed upwards is counterbalanced by the momentum source causing a counterclockwise flow circulation in the pool. Although the momentum source is the same as in Case $2 \mathrm{a}$, complete mixing is observed in Case $2 \mathrm{~b}$ as opposed to Case $2 \mathrm{a}$. The time scale of mixing for Case $2 \mathrm{~b}$ is about $600 \mathrm{~s}$ compared to about $550 \mathrm{~s}$ in the STB-21 experiment. With the maximum momentum rate and uniform heat flux, complete mixing is observed a bit later at about $950 \mathrm{~s}$. This is mostly due to apparent higher resistance to mixing in the top of the stratified layer. However, mixing of the bottom layer occurs faster than in Case $2 b$ with lesser momentum rate.

Given the uncertainties in the input conditions, the above discussion demonstrates the robustness of the EHS and EMS models which captures interplay of competing effects, heat and momentum sources, and allows getting reasonable agreement with the experimental data. All results obtained with EHS/EMS are in fact not far off from reality. In the next section we discuss application of EHS-EMS models which yield even better predictions when experimental measurement uncertainties are significantly reduced.

\section{Validation of EHS and EMS Models against PPOOLEX MIX-01 Test}

The MIX-01 test consists mainly of three phases, namely, the clearing phase, stratification phase, and finally the mixing phase (see Figure 12) which are related to the steam flow rates. During the test, the steam mass flow rates are measured in the steam line and not in the inlet of the blowdown pipe. Thus, the measured steam flow rate is not necessarily the same as the steam flow rate from the drywell to the wetwell through the blowdown pipe. This is especially true during the clearing phase as the drywell is initially cold (about $28^{\circ} \mathrm{C}$ ) and filled with noncondensable gases. During the clearing phase, steam pushes all the noncondensable gases from the drywell to the wetwell first while steam condenses on the drywell walls and heats up the drywell compartment. For example, at $\sim 200 \mathrm{~g} / \mathrm{s}$ steam mass flow rate, a transient time of $\sim 500 \mathrm{~s}$ (which is the time period that is set for the clearing phase) is more than enough to push all the gas to the wetwell. After the clearing phase, it is expected that the steam flow rate in the steam line is almost the same as the steam flow rate to the wetwell and this is found in GOTHIC lumped simulations taking into account the insulated drywell.

A GOTHIC lumped calculation has confirmed that at low steam mass flow rates, less than $100 \mathrm{~g} / \mathrm{s}$ (typically during the stratification phase), the flow meter in the PPOOLEX facility provided inaccurate readings. This corroborates also with estimation of the water level in the pool. Using the measured steam mass flow rates during the stratification phase, the predicted average temperature as well as the water level in the pool increases much faster in the lumped simulation 

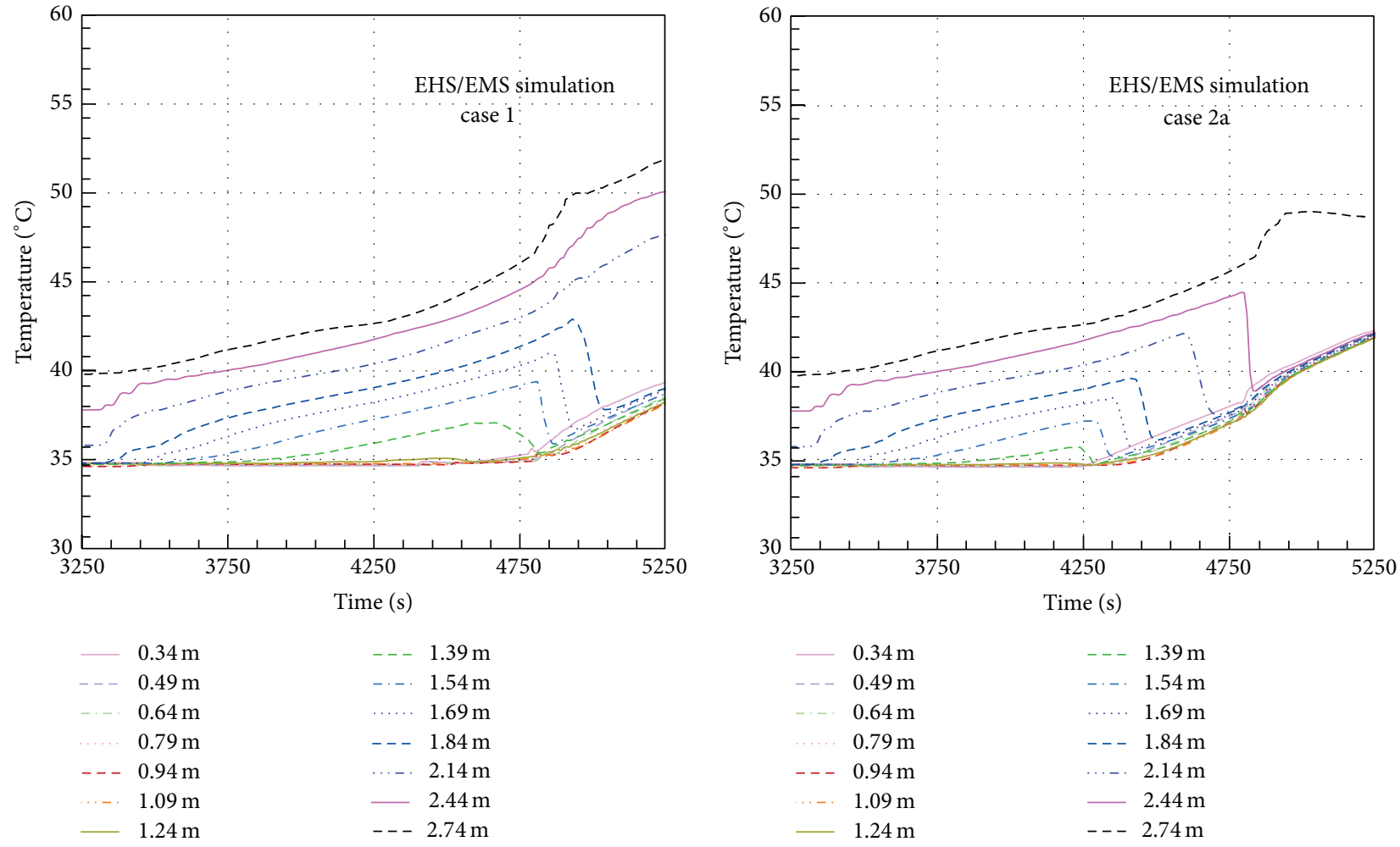

(a)
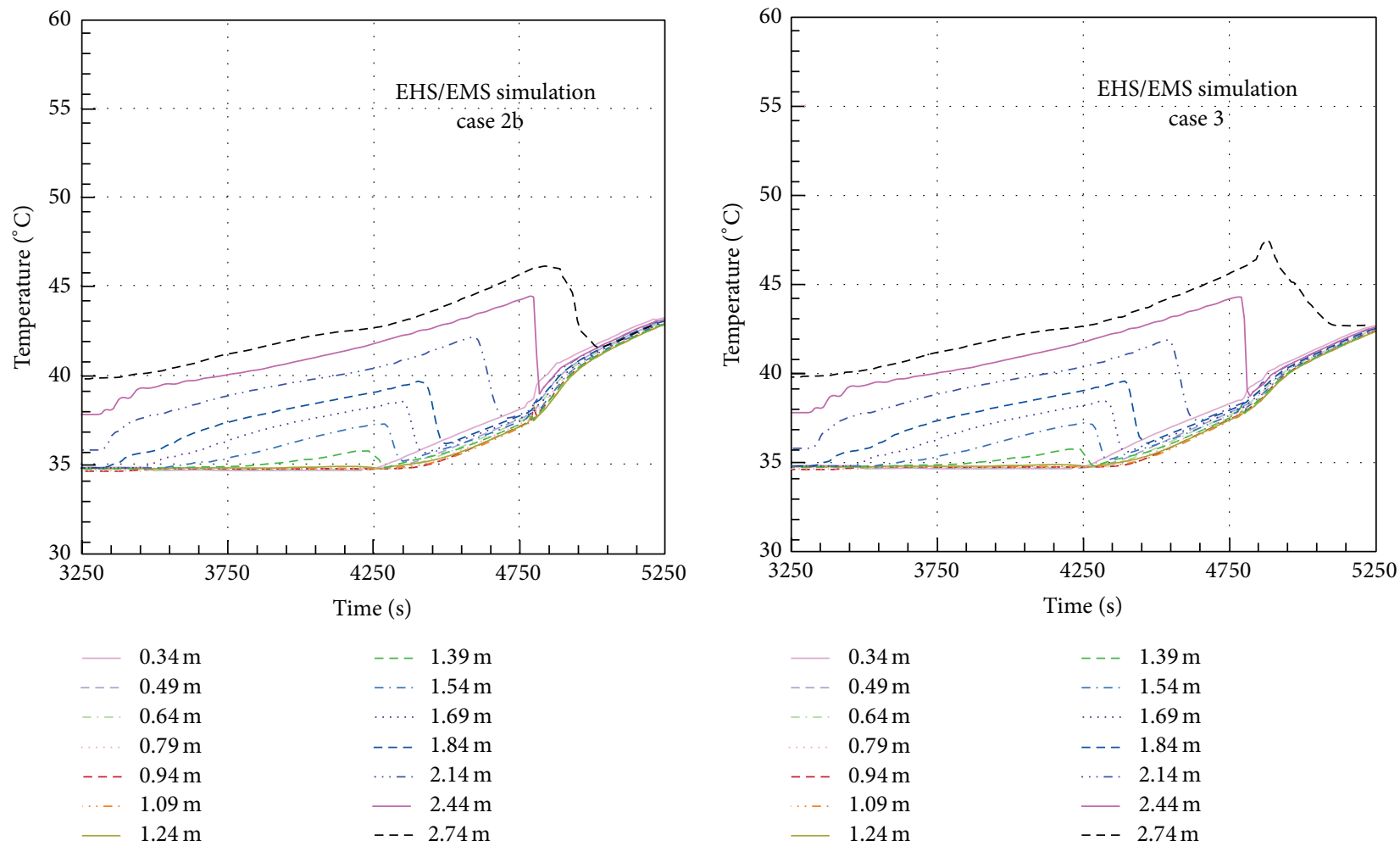

(c)

(d)

FIGURE 11: Comparison of different cases of EHS/EMS simulations: (a) Case 1 corresponds to the minimum momentum rate with uniform heat flux on the pipe's submerged surface, (b) Case 2a corresponds to a chosen momentum rate between the minimum and maximum values with also uniform heat flux on the pipe's submerged surface, (c) Case $2 b$ is the same as Case $2 a$ except that the heat flux shifts from the pipe's submerged surface to the pipe's exit, and (d) Case 3 corresponds to the maximum momentum rate with also uniform heat flux on the pipe's submerged surface. 


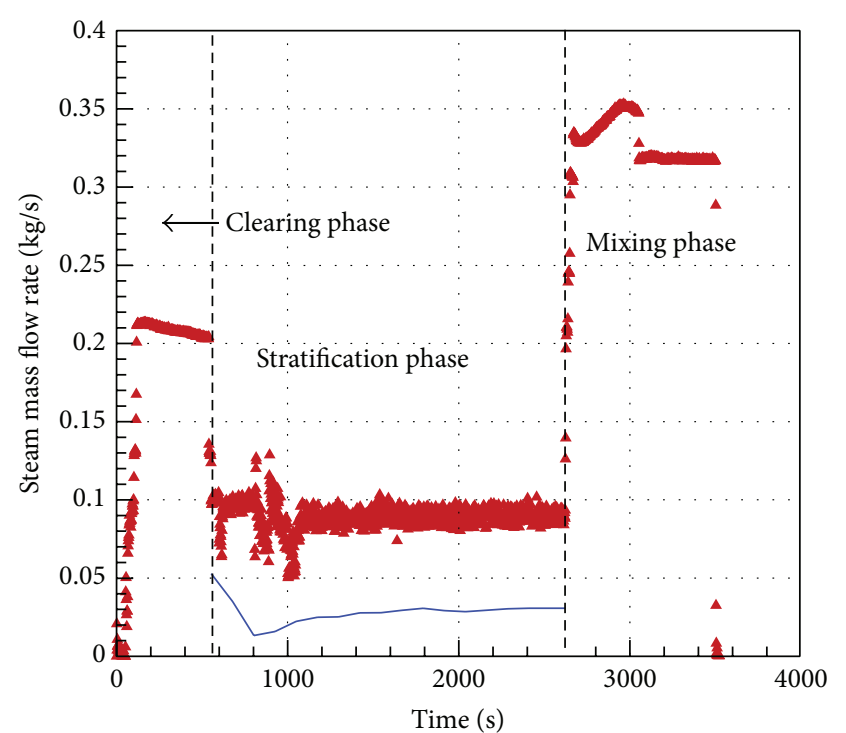

- Flow meter Water level

FIGURE 12: Measured steam mass flow rates with (i) flow meter and (ii) water level in the pool, during the MIX-01 experiment.

than in the experiment. To resolve this issue, the steam mass flow rates are estimated based on the collapsed water level in the pool (which takes into account the variable water level in the blowdown pipe and dependence of the densities on the increasing temperature in the pool); see Figure 12. The estimated flow rates during the stratification phase and the measured steam flow rates during the mixing phase are then used as input for the EHS-EMS simulation.

In the MIX tests, more thermocouples are installed inside the blowdown pipe to monitor the water level change during the oscillation in the mixing phase. The measurement frequency is much higher $(20 \mathrm{~Hz})$ than before. Compared to the STB-21 test, the oscillation pattern inside the blowdown pipe can be well captured (see Figure 9). Thus the estimation of the water level position inside the pipe is more accurate in MIX-01 than in STB-21.

It should be noted from this point forward that the initial time $t=0 \mathrm{~s}$ in the simulations (as evident in succeeding figures) corresponds to time $1100 \mathrm{~s}$ in Figure 12. The start of the mixing phase in the simulation is at time $t=1573 \mathrm{~s}$. Figure 13 shows the effective momentum rates based on the water level oscillations in the pipe during the mixing phase in MIX-01 test. Described briefly, the TC measurements are converted to water level positions and then velocities can be calculated by taking time derivatives. Effective (jet) velocities are calculated based on the synthetic jet theory. Finally, effective momentum rates can be directly calculated. As shown in Figure 13, the nonconstant momentum rates are between 12 and $21 \mathrm{~kg} \cdot \mathrm{m} / \mathrm{s}^{2}$ which are based on effective jet velocities between 0.59 and $0.77 \mathrm{~m} / \mathrm{s}$.

The GOTHIC model schematic is shown in Figure 14(a) while the $48 \times 75$ mesh of the wetwell is shown in Figure 14(b). A thermal conductor is used to provide heat transfer through

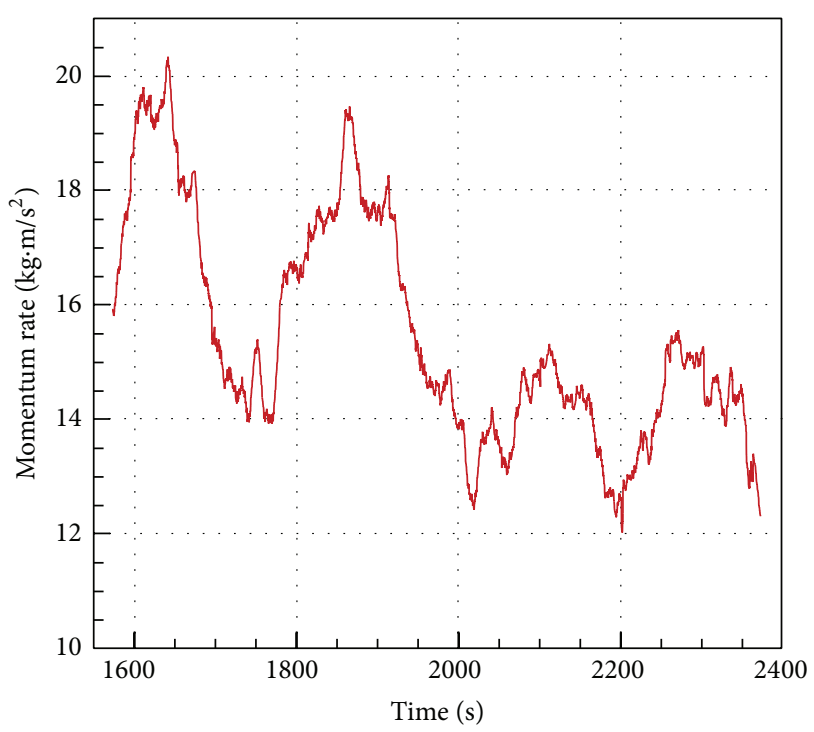

FIGURE 13: Effective momentum rates based on the water level oscillations in the pipe during the chugging (mixing) phase in MIX01 test.

the bottom wall of the drywell and is used in boundary conditions at the top of the wetwell gas space. The floor surface temperature of the drywell is measured during the experiment and this is used as boundary condition at the top of the wetwell. The clearing phase has resulted in complete mixing in the pool and has also generated a strong circulation flow that took time to stagnate, about $\sim 600 \mathrm{~s}$ after the steam flow rate has been decreased. The EHS-EMS calculation only includes part of the thermal stratification and mixing phases and excludes the clearing phase as mentioned above. The calculation time is about 3 hours on 4 processors of an i7 3.4 GHz desktop.

In Figure 15(a), the averaged liquid temperature in the pool predicted by the EHS-EMS simulation shows an excellent match against the MIX-01 data. At time $t=0 \mathrm{~s}$, the averaged liquid temperature is about $16^{\circ} \mathrm{C}$ and it increases to $19.5^{\circ} \mathrm{C}$ during the stratification phase compared to $19.2^{\circ} \mathrm{C}$ in the simulation. The increase in temperature is more pronounced during the mixing phase where it reaches $39.5^{\circ} \mathrm{C}$ while the predicted temperature is $39^{\circ} \mathrm{C}$. Even the predicted increase in water level in the pool (see Figure 15(b)) shows an excellent match. The initial water level is at $2.11 \mathrm{~m}$ and during the stratification phase increases to only $2.12 \mathrm{~m}$ while the predicted water level is also at $2.12 \mathrm{~m}$. And during the mixing phase, the water level shows an abrupt increase to $2.2 \mathrm{~m}$ while the predicted water level is $2.19 \mathrm{~m}$. This also confirms that the heat losses through the wetwell walls are modeled properly.

Figure 16 shows the comparison in pool temperature between the MIX-01 measured data and EHS-EMS simulation. In general, the predicted pool temperature agrees very well with the measured data. Of course the small fluctuations in the TC measurements are not captured in the simulation. The development of thermal stratification in different layers is well captured in the simulation except for the small region in the vicinity of the pipe outlet (from heights of $1.16 \mathrm{~m}$ 


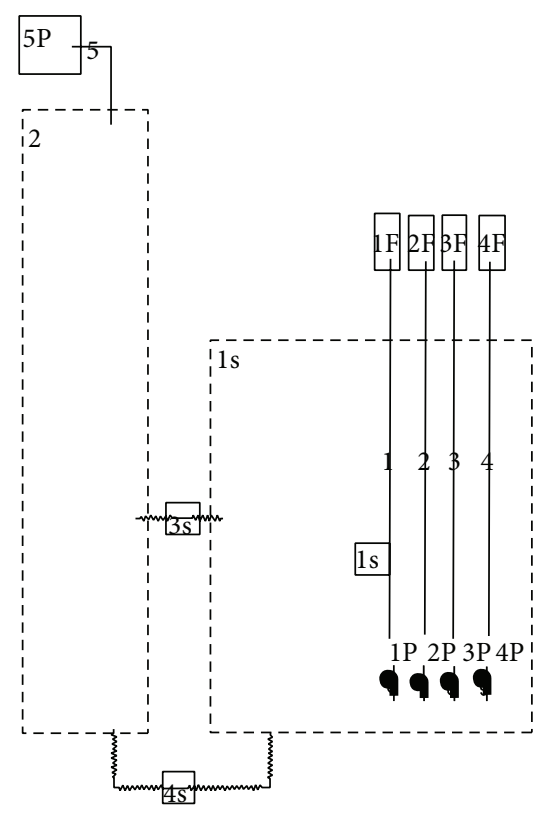

(a)

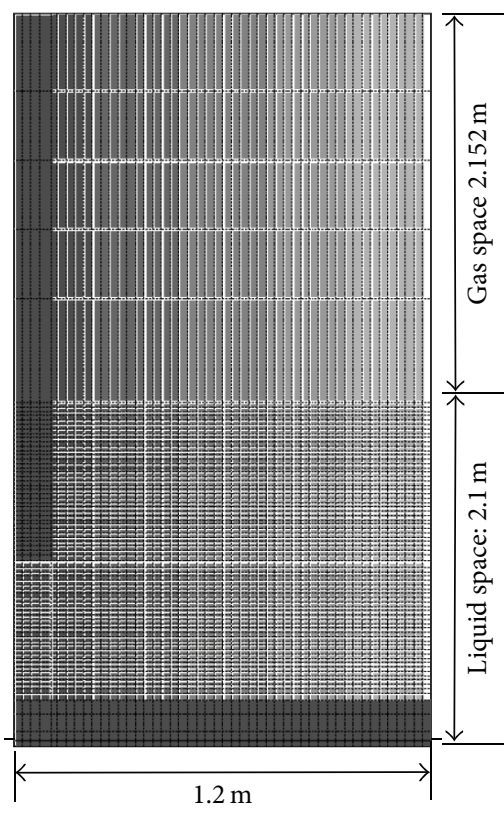

(b)

FIGURE 14: (a) GOTHIC model schematic of MIX-01 and (b) corresponding 2D mesh with $48 \times 75$ for the wetwell.

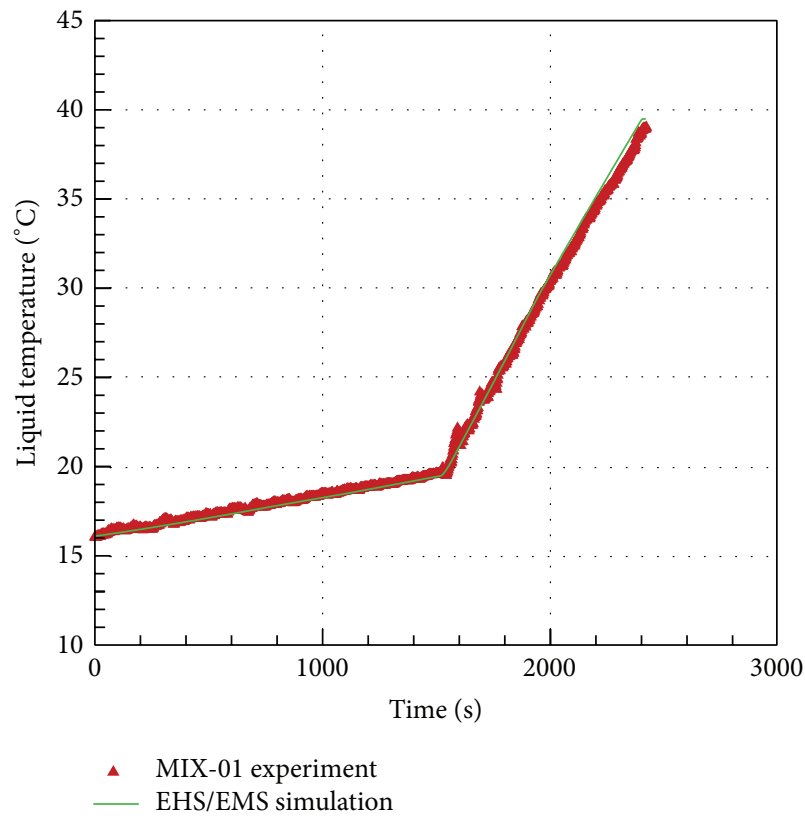

(a)

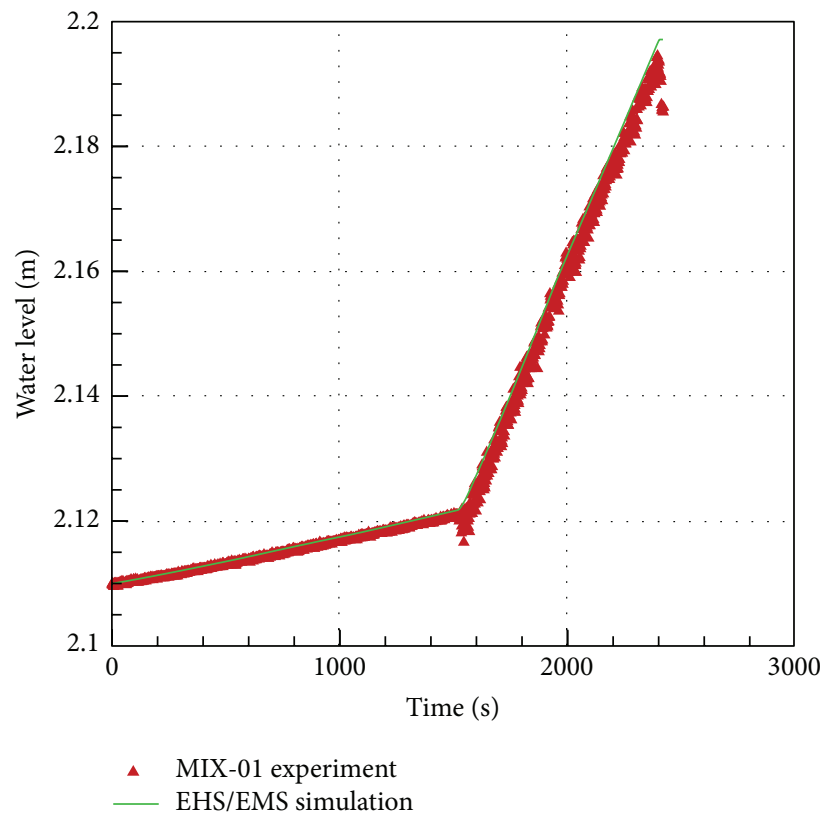

(b)

FIGURE 15: Comparison between EHS-EMS simulation results and MIX-01 test on (a) averaged liquid temperature and (b) water level in the wetwell pool.

to $1.43 \mathrm{~m}$ ) which is attributed to the uniform heat flux distribution assumed in the simulation. A nonuniform heat flux distribution due to nonuniform condensation inside the pipe is a subject for further study. In addition, the temperature behavior at the top layer of the wetwell pool (which is an important quantity in plant safety that can affect operator actions) is quite well predicted in the simulation. At the end of the stratification phase, the predicted temperature at the top layer is about $27^{\circ} \mathrm{C}$ while the measured temperature is about $28^{\circ} \mathrm{C}$. As a result of higher steam flow rates and transition of the condensation regime to chugging, there is a strong circulation flow in the pool which leads to complete mixing. In the simulation, the time scale for mixing is about $200 \mathrm{~s}$ while in the MIX-01 experiment it is about $250 \mathrm{~s}$. Part 


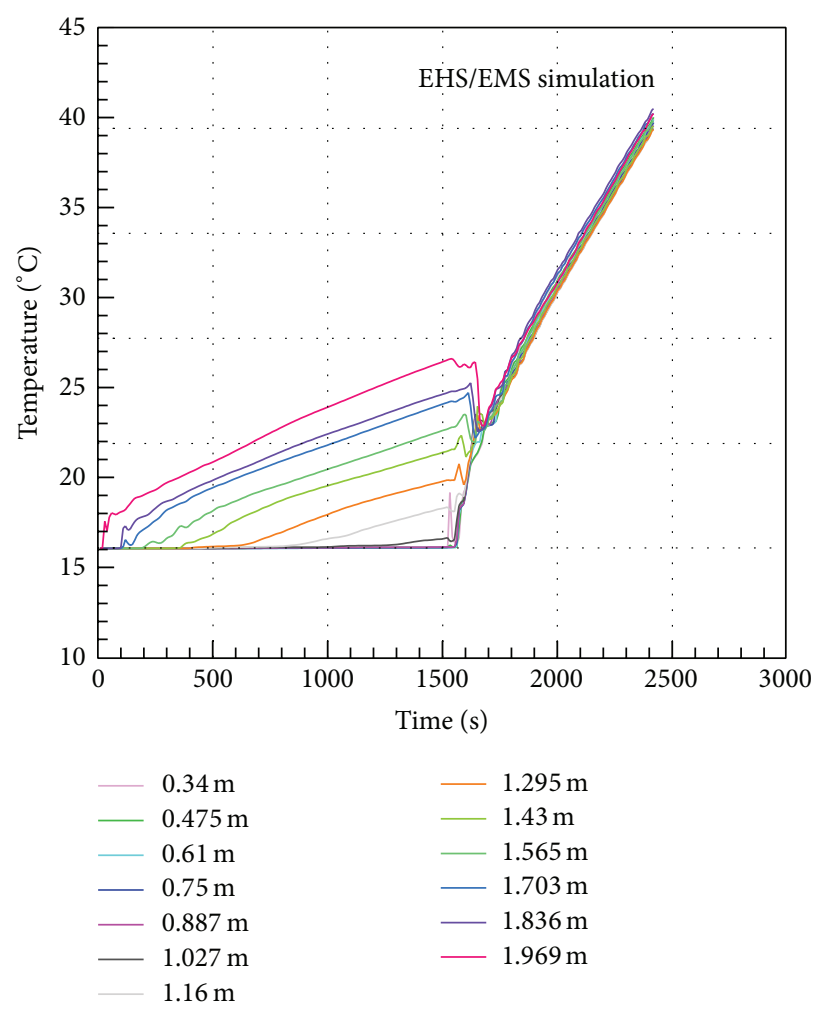

(a)

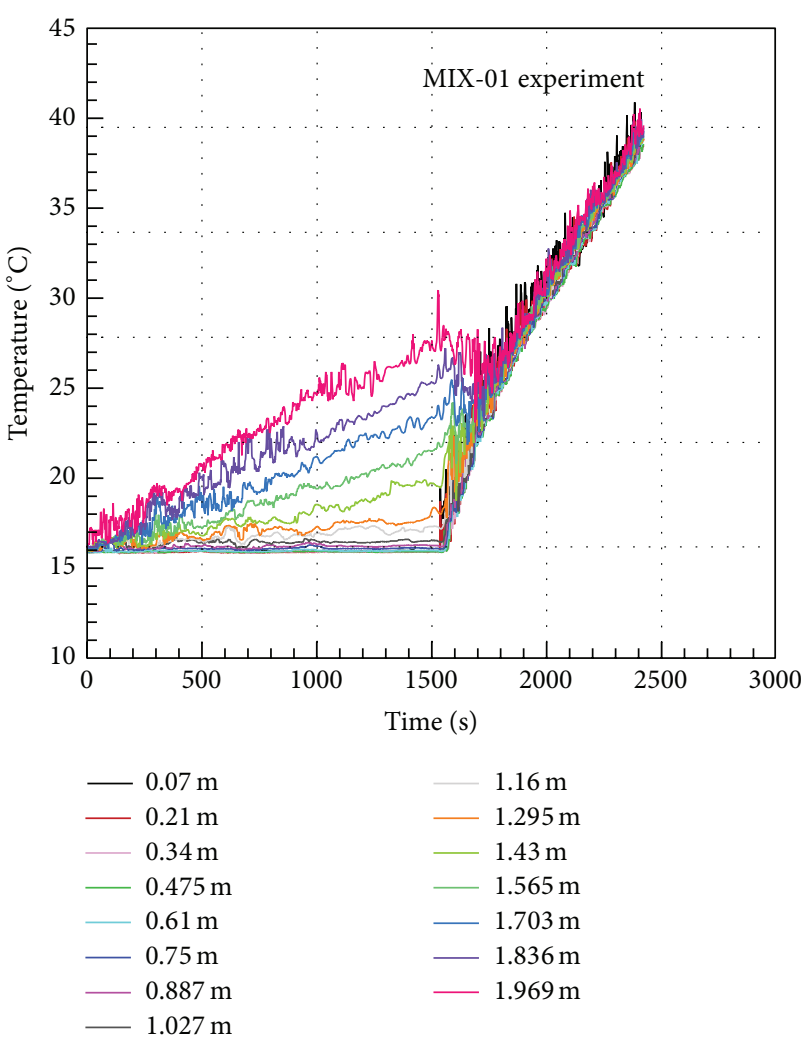

(b)

FIGURE 16: Comparison of pool temperature between (a) EHS-EMS simulation and (b) MIX-01 measured data. The level of the pipe outlet is at $1.045 \mathrm{~m}$.

of the reason is the slight $(\sim 1$ degree) underprediction of temperature difference between the top and bottom layers at the end of the stratification phase. Another possible reason is the small overestimation of the momentum rate during the mixing phase.

A more detailed comparison of the temperature behavior in the pool is shown in Figure 17. In Figure 17(a), the temperature profiles of the middle (about $0.48 \mathrm{~m}$ from the bottom) and bottom layers in both the EHS-EMS simulation and MIX-01 experiment are shown. In the simulation, the bottom of the tank is modeled as a flat plate to simplify implementation given that GOTHIC only supports Cartesian coordinate system. For the comparison, the corresponding locations of the bottom and middle layers are then adjusted accordingly. As can be seen in the figure, the bottom layers in both the simulation and experiment are higher than the middle layers. This is caused by the downward flow of heated water right from the blowdown pipe outlet (and can be clearly seen in Figure 18(c)). The temperature at the bottom layer though is 2-3 degrees higher in the simulation than in the experiment. In Figure 17(b), a snapshot of the vertical temperature profile near the end of the thermal stratification phase (at time $t=1500 \mathrm{~s}$ ) is shown. Both the experiment and simulation show that the layer below the pipe outlet remains cold (about $16^{\circ} \mathrm{C}$, same as initial) while the upper layer develops thermal stratification.
Figure 18 shows snapshots of the predicted temperature and velocity profiles at different times $t=1000 \mathrm{~s}$ (stratification phase), $t=1540 \mathrm{~s}$ (early mixing phase), and $t=1600 \mathrm{~s}$ (mixing phase). At $t=1000 \mathrm{~s}$, the upper layer develops a thermally stratified layer mainly due to the heating of the water surrounding the pipe creating a buoyant plume of hot water circulating in a clockwise manner, while the lower layer remains cold as mentioned earlier. The magnitude of the maximum velocity at this time is just $0.06 \mathrm{~m} / \mathrm{s}$. At $t=1540 \mathrm{~s}$, the development of thermal stratification can still be observed but a jet directed downwards is clearly visible and responsible for the developing counterclockwise flow circulation. The magnitude of the maximum velocity at this time has increased to about $0.46 \mathrm{~m} / \mathrm{s}$. During the mixing phase at $t=1600 \mathrm{~s}$, the counterclockwise flow circulation becomes more prominent due to the dominant effect of the jet from the pipe outlet. The magnitude of the maximum velocity at this time is also about $0.45 \mathrm{~m} / \mathrm{s}$. As mentioned earlier, the jet directed downwards transports hot water to the bottom layer which is also observed in the experiment.

\section{Summary and Conclusions}

In this work, the Effective Heat Source (EHS) and Effective Momentum Source (EMS) models are implemented 


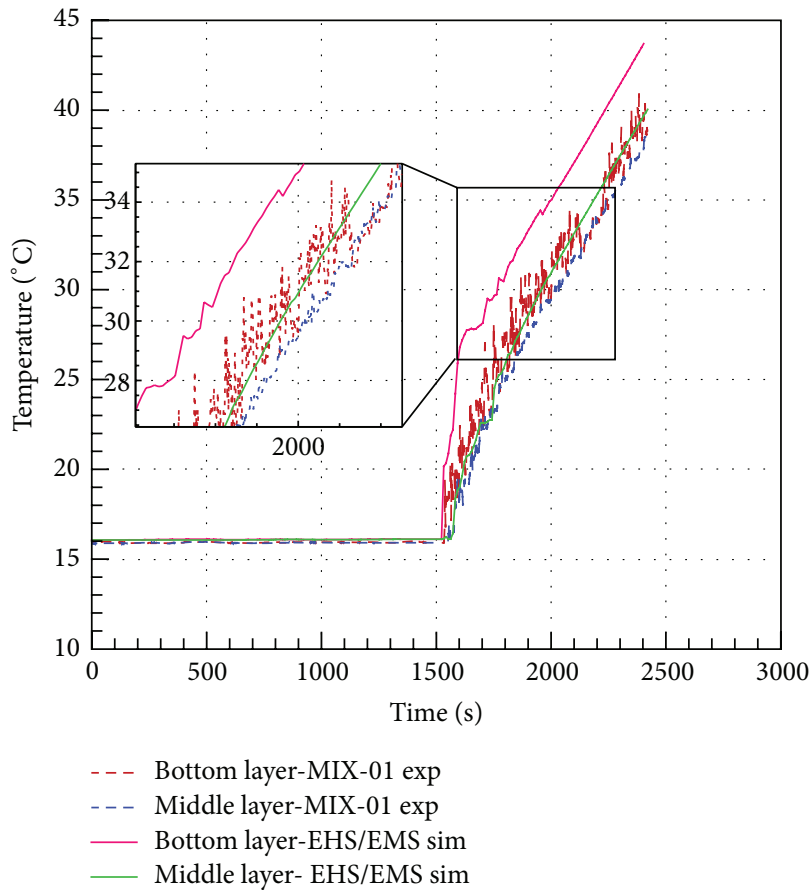

(a)

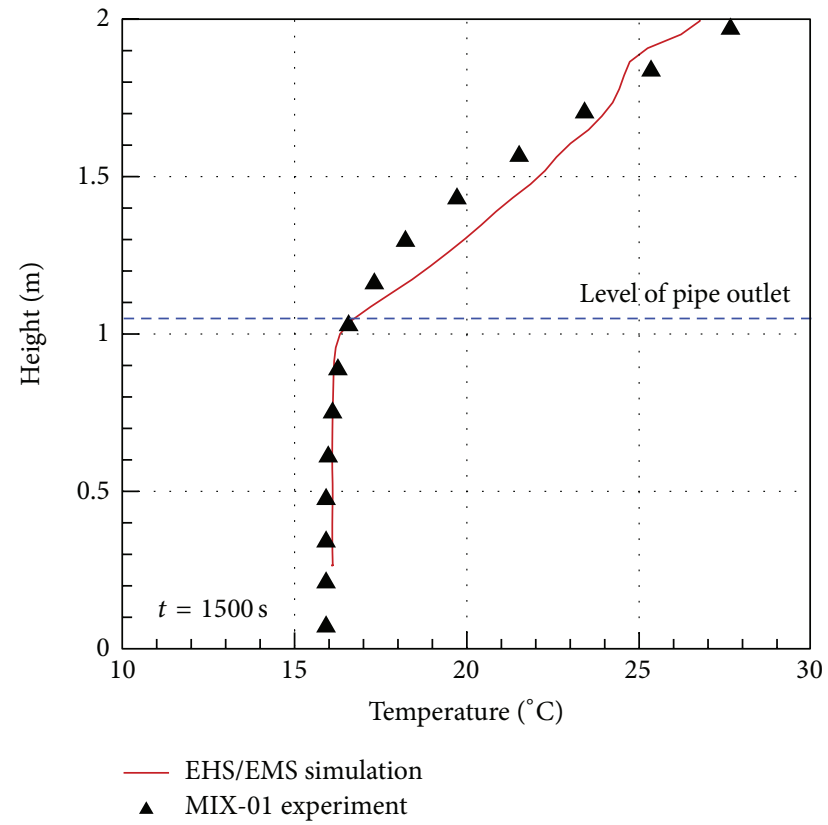

(b)

FIGURE 17: Comparison of pool temperature (a) at selected levels in the pool and (b) snapshot of vertical temperature profile at time $t=1500 \mathrm{~s}$.

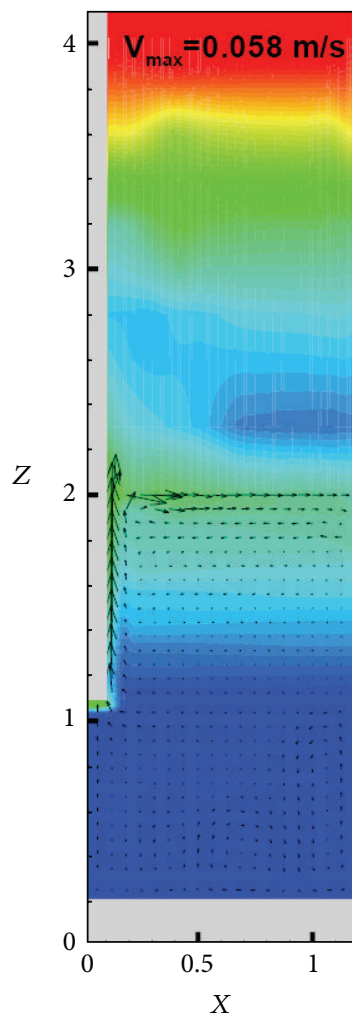

(a) $t=1000 \mathrm{~s}$

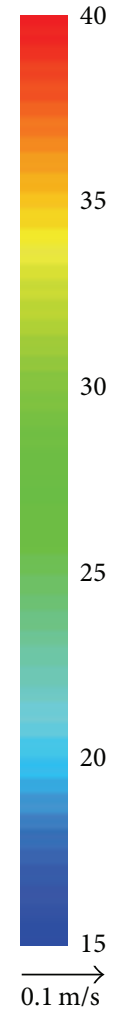

30

25

20

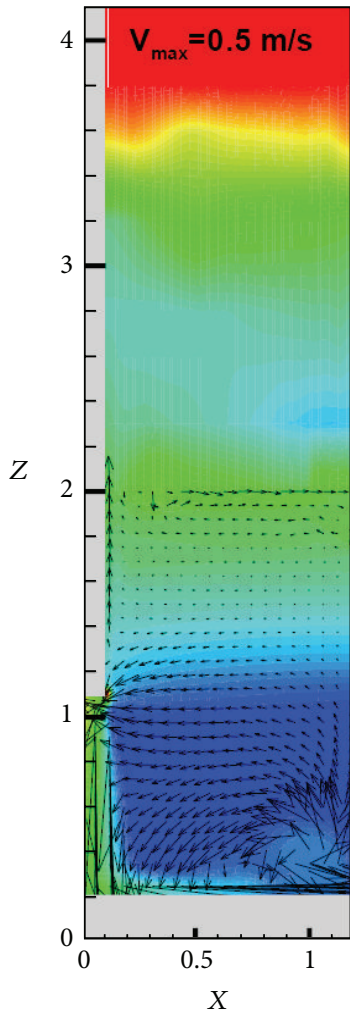

(b) $t=1540 \mathrm{~s}$

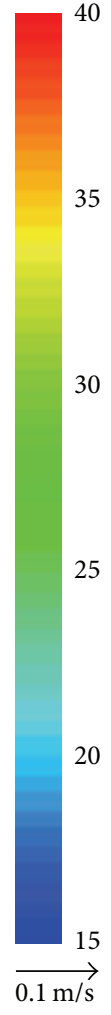

T

25

20
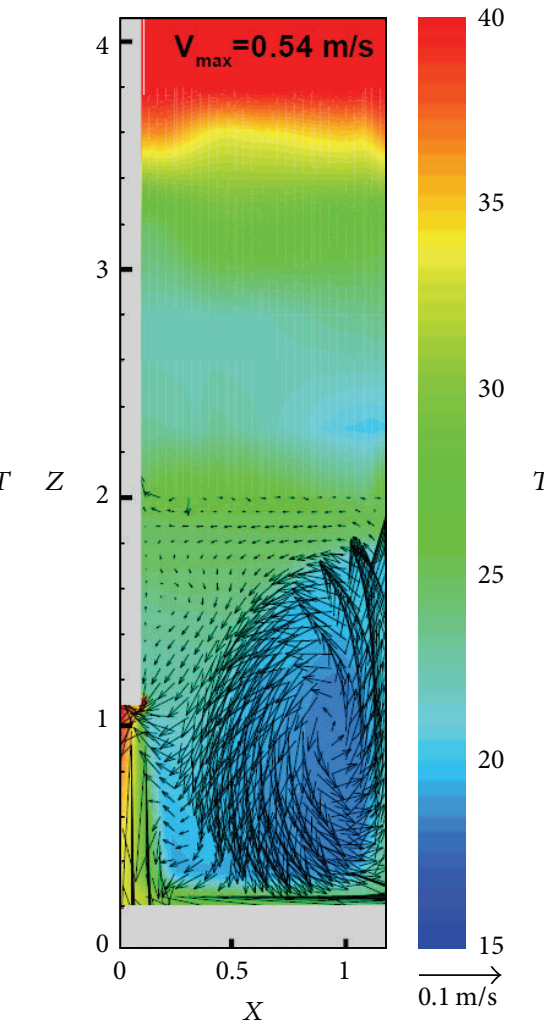

(c) $t=1600 \mathrm{~s}$

FigURE 18: EHS-EMS simulation snapshots of temperature profiles with superimposed velocity fields at different times (a) $t=1000 \mathrm{~s}$, during stratification phase, (b) $t=1540 \mathrm{~s}$, early stage of mixing phase, and (c) $t=1600 \mathrm{~s}$, during mixing phase. 
in GOTHIC and validated against the POOLEX STB-20 and STB-21 tests and also the PPOOLEX MIX-01 test on thermal stratification and mixing induced by steam injection into a large pool of water. First, the EHS model is validated against the STB-20 test which shows the development of thermal stratification only. Different numerical order schemes and grid resolutions have been tested. A $48 \times 114$ grid $(5472$ cells) is enough to obtain very good agreement with the experimental data and a second order scheme is needed to capture the vertical temperature distribution in the pool. Next, the EHS and EMS are validated against the STB-21 test. The space and time resolution of temperature measurements inside the blowdown pipe is insufficient in this test. However, an effective momentum selected within the experimental uncertainty can still reproduce the mixing details. In addition, the transition between different EMS regimes corresponds to the transition to different condensation regimes. Finally, the EHS-EMS models are validated against the MIX-01 test which has much better space and time resolution of temperature measurements inside the blowdown pipe. Excellent agreement in averaged pool temperature and water level in the pool between the experiment and simulation has been achieved. The development of thermal stratification in the pool is also well captured in the simulation as well as the mixing phase. Moreover, the heating up of the bottom layer due to the impinging jet of hot water is also observed in both the simulation and experiment.

For future work, the EHS-EMS models for blowdown pipes will be improved further in order to reduce uncertainties and improve accuracy in predictions. Specifically, modifications of the EHS model for nonuniform condensation inside the blowdown pipe will be addressed. For the EMS model, proper extension of existing models for prediction of frequency and amplitude of oscillations (given only the condensation regime and design specific parameters) will be performed. It should be pointed out that experimental data is limited for validation of such models. The only available and sufficiently detailed experimental data are the POOLEX/PPOOLEX experiments.

\section{Appendix}

\section{Validation of Aya and Nariai for Prediction of Amplitude and Frequency of the Oscillation in PPOOLEX Tests}

Prediction of the amplitude and frequency of the free surface oscillations in the pipe for specific steam condensation regime is necessary if such characteristics are not known from an experiment. Aya and Nariai $[14,18,19]$ have studied experimentally and analytically the frequency and amplitude of fluid oscillations in different condensation regimes. In particular, Figure 19 shows a sketch of their analytical model for chugging [14]. A 1D model of the water level oscillation in the blowdown pipe has been derived from conservation laws

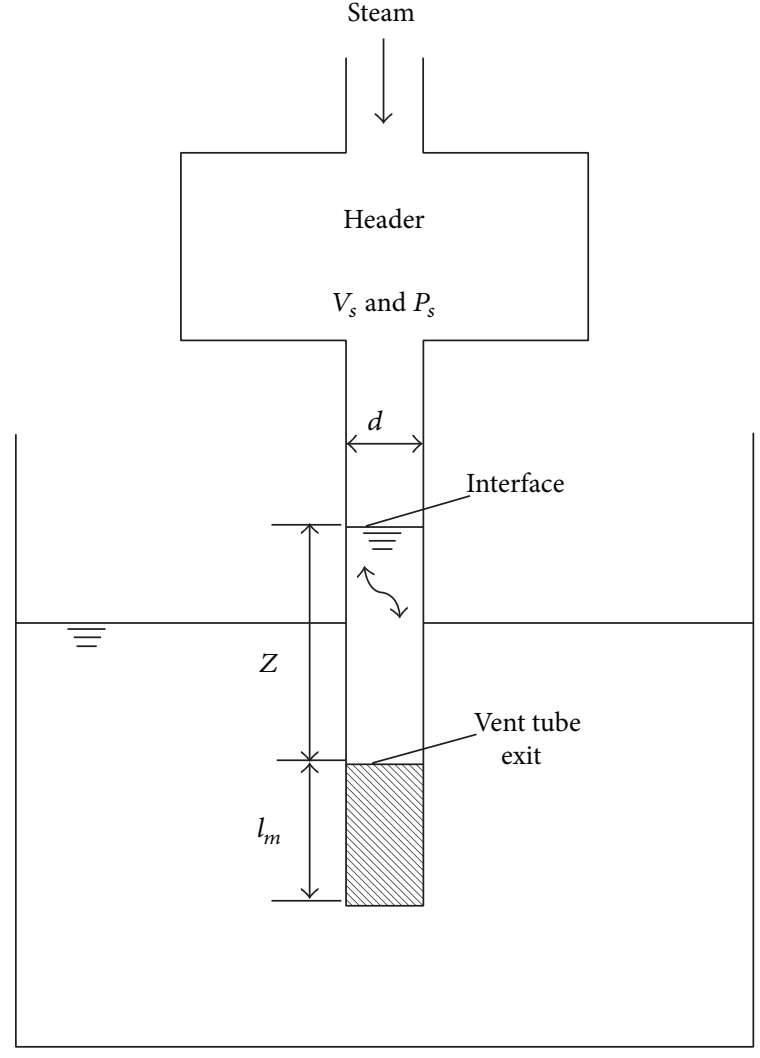

FIGURE 19: Analytical model for large chugging [14].

neglecting the condensation in the continuity equation and given as

$$
\frac{d^{3} z}{d t^{3}}+\omega_{c}^{2} \frac{d z}{d t}+D=0
$$

where the frequency $\omega_{c}$ and coefficient $D$ are

$$
\begin{gathered}
\omega_{c}^{2}=\frac{g}{\bar{z}+l_{m}}\left(1+\frac{\pi \kappa P_{s 0} d^{2}}{4 \rho_{L} g V_{s}}\right), \\
D=\frac{\pi \kappa G_{0} P_{s 0} d^{2}}{4 \rho_{L} \rho_{s 0}\left(\bar{z}+l_{m}\right) V_{s}},
\end{gathered}
$$

and $\bar{z}$ is the averaged water level taken as $\bar{z}=0.5 z_{\max }$. The densities of liquid and steam are denoted by $\rho_{L}$ and $\rho_{s}$, respectively. Also, $G_{0}, d, V_{s}, P, \kappa$, and $l_{m}$ are the steam mass flow rate, diameter of the pipe, volume of header, pressure, ratio for specific heat for steam, and inertia length of pool water, respectively. The particular solution when $z=0$ at $t=0$ is given as

$$
z(t)=C \cdot \sin \left(\omega_{c} t\right)-\frac{D}{\omega_{c}^{2}} t,
$$

where $C$ is the maximum elevation of the interface. In addition, Nariai and Aya $[14,18]$ have presented comparisons of the above analysis against experimental data in small systems (with blowdown pipe diameters around $18 \mathrm{~mm}$ and 


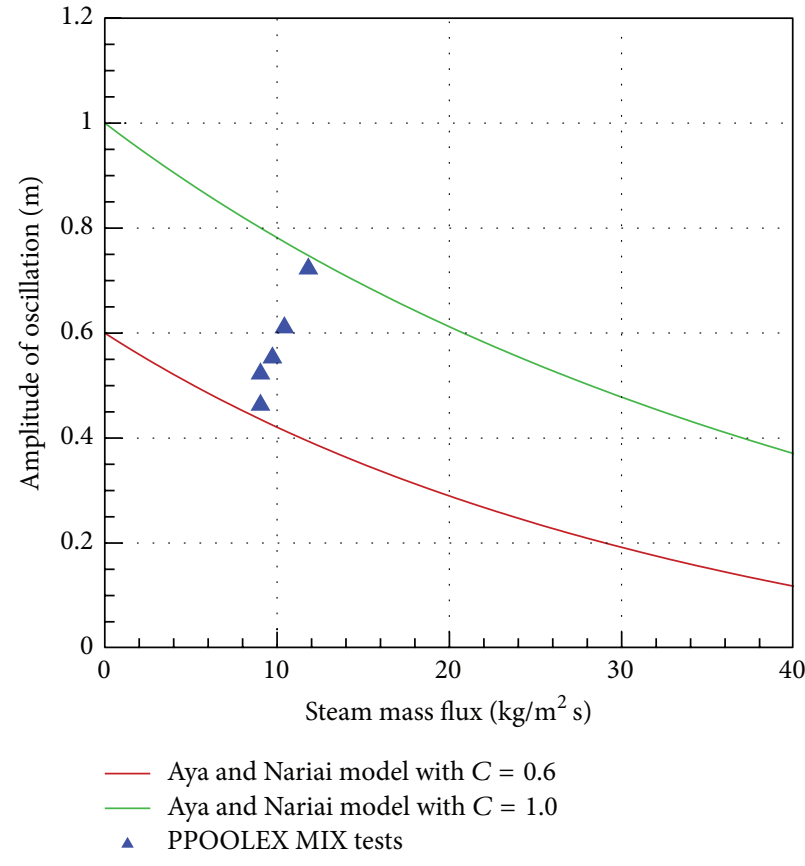

(a)

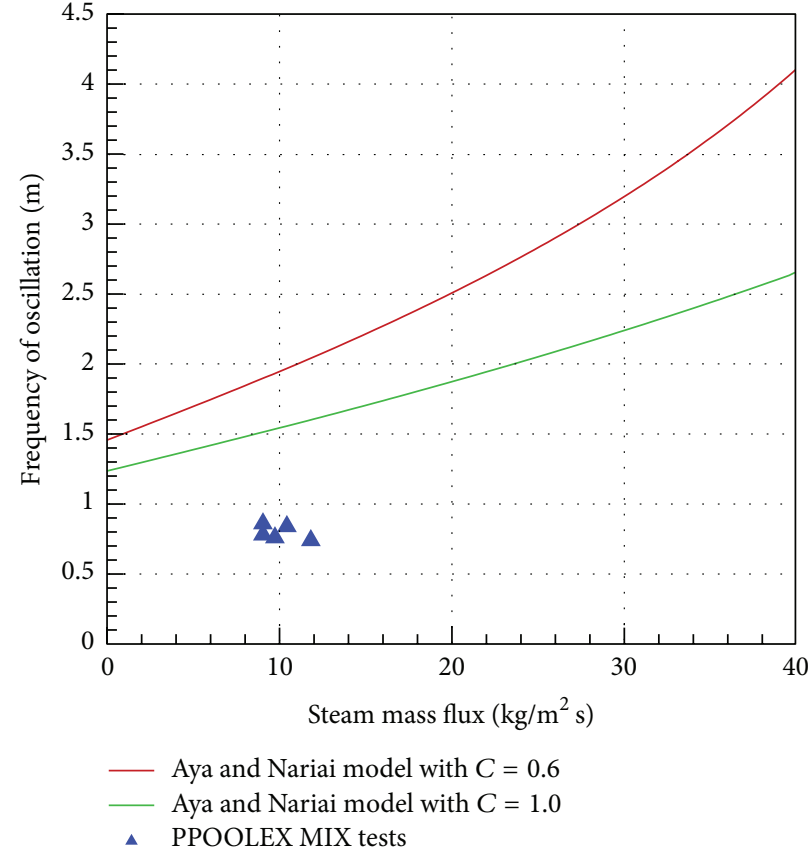

(b)

Figure 20: (a) Amplitude and (b) frequency of oscillations in the pipe: comparisons between Aya and Nariai model predictions and estimations based on TC measurements inside the pipe of the PPOOLEX MIX tests.

header volumes around $0.02 \mathrm{~m}^{3}$ ). For a particular coefficient $C=0.4 \mathrm{~m}$, they have found better agreement in frequency of oscillations at lower temperatures between 20 and $30^{\circ} \mathrm{C}$ and in amplitude of oscillations at steam mass fluxes higher than $3 \mathrm{~kg} /\left(\mathrm{m}^{2} \mathrm{~s}\right)$.

In Figure 20, comparisons of the Aya and Nariai model predictions against the PPOOLEX MIX tests are shown. Since there is only one equation (A.1) governing the water level position, the coefficient $C$ has to be chosen first and then the amplitude and frequency of oscillations can be calculated. In Figure 20(a), two values of $C=0.6$ and $1.0 \mathrm{~m}$ have been chosen while the rest of the parameters in (A.2) have been set according to the PPOOLEX MIX tests conditions and design parameters. The amplitude of oscillations in the PPOOLEX MIX tests taken at certain time windows (with steam mass fluxes around $10 \mathrm{~kg} /\left(\mathrm{m}^{2} \mathrm{~s}\right)$ ) are scattered between the $C=0.6$ and $1.0 \mathrm{~m}$ analytical curves with Aya and Nariai model. A similar increasing tendency is observed in Aya and Nariai's experiment [18] but for steam mass fluxes lower than $3 \mathrm{~kg} /\left(\mathrm{m}^{2} \mathrm{~s}\right)$. In Figure 20(b), the corresponding frequency of oscillations plotted against the steam mass flux for both $C=0.6$ and $1.0 \mathrm{~m}$ analytical curves with the Aya and Nariai model is shown. The analytical model significantly overpredicts the frequency of oscillations in the PPOOLEX MIX tests. The main difference between the Aya and Nariai experiments and PPOOLEX experiments is the characteristic scale of the systems. In particular, the diameter of the pipe in the PPOOLEX experiments is an order of magnitude higher than in the Aya and Nariai experiments. Obtained results suggest that further investigation of the scalability of the Aya and Nariai model is necessary. Such task is beyond the scope of this study but is currently being undertaken. Also other models can be considered as candidates for prediction of the amplitude and frequency of the oscillations in the EMS model.

\section{Conflict of Interests}

The authors declare that there is no conflict of interests regarding the publication of this paper.

\section{Acknowledgments}

This work was performed within the RM3 project funded by NORTHNET, Sweden, and the ENPOOL project funded by the Nordic Nuclear Safety Research (NKS). GOTHIC is developed and maintained by the Numerical Applications Division of Zachry Nuclear Engineering under EPRI sponsorship. The authors would like to acknowledge NAI for providing access to the program for educational and research purposes.

\section{References}

[1] R. E. Gamble, T. T. Nguyen, B. S. Shiralkar, P. F. Peterson, R. Greif, and H. Tabata, "Pressure suppression pool mixing in passive advanced BWR plants," Nuclear Engineering and Design, vol. 204, no. 1-3, pp. 321-336, 2001.

[2] Y. Kataoka, T. Fukui, and S. Hatamiya, "Experimental study on convection heat transfer along a vertical flat plate between 
different temperature pools," in Proceedings of the ANS National Heat Transfer Conference, pp. 28-31, Minneapolis, Minn, USA, July 1991.

[3] R. J. Fox, "Temperature distribution in pools with shallow buoyant jets," in Proceedings of the 5th International Topical Meeting on Nuclear Reactor Thermal Hydraulics (NURETH-5), pp. 1227-1234, Salt Lake City, Utah, USA, September 1992.

[4] B. L. Smith, T. V. Dury, M. Huggenberger, and N. Nöthiger, "Analysis of single-phase mixing experiments in open pools," in Thermal Hydraulics of Advanced and Special Purpose Reactors, ASME HTD, F. B. Cheung and P. F. Peterson, Eds., vol. 209, pp. 91-100, ASME, New York, NY, USA, 1992.

[5] T. L. Norman, H.-S. Park, S. T. Revankar, M. Ishii, and J. M. Kelly, "Thermal stratification and mixing in an open water pool by submerged mixtures of steam and air," in Proceedings of the ASME International Mechanical Engineering Congress and Exposition (IMECE '06), November 2006.

[6] C. Ling, S. W. Kyoung, M. Ishii, J. Lim, and J. Han, "Suppression pool mixing and condensation tests in PUMA facility," in Proceedings of the14th International Conference on Nuclear Engineering (ICONE '14), pp. 355-365, Miami, Fla, USA, July 2006.

[7] J. Laine and M. Puustinen, "Thermal stratification experiments with the condensation pool test rig," NKS-117, 2006.

[8] J. Laine, M. Puustinen, and A. Räsänen, "PPOOLEX experiments on dynamics of free water surface in the blowdown pipe," Research Report EXCOP 2/2012, NKS-281, 2013.

[9] P. F. Peterson, "Scaling and analysis of mixing in large stratified volumes," International Journal of Heat and Mass Transfer, vol. 37, no. 1, pp. 97-106, 1994.

[10] H. Zhao, Computation of mixing in large stably stratified enclosures [Ph.D. thesis], University of California, Berkeley, Calif, USA, 2003.

[11] H. Zhao and P. F. Peterson, "One-dimensional analysis of thermal stratification in AHTR and SFR coolant pools," in Proceedings of the 12th International Topical Meeting on Nuclear Reactor Thermal Hydraulics (NURETH '12), Pittsburgh, Pa, USA, September 2007.

[12] H. Li, W. Villanueva, and P. Kudinov, "Validation of effective momentum and heat flux models for stratification and mixing in a water pool," Nordic Nuclear Safety Research, Research Report NKS-284, 2013.

[13] H. Li, W. Villanueva, and P. Kudinov, "Approach and development of effective models for simulation of thermal stratification and mixing induced by steam injection into a large pool of water," Science and Technology of Nuclear Installations, vol. 2014, Article ID 108782, 11 pages, 2014.

[14] H. Nariai and I. Aya, "Fluid and pressure oscillations occuring at direct contact condensation of steam flow with cold water," Nuclear Engineering and Design, vol. 95, pp. 35-45, 1986.

[15] R. T. Lahey and F. J. Moody, The Thermal Hydraulics of a Boiling Water Reactor, American Nuclear Society, La Grange Park, Ill, USA, 2nd edition, 1993.

[16] B. L. Smith and G. W. Swift, "A comparison between synthetic jets and continuous jets," Experiments in Fluids, vol. 34, no. 4, pp. 467-472, 2003.

[17] B. Smith and G. Swift, "Synthetic jets at larger reynolds number and comparison with continuous jets," in Proceedings of the 31st AIAA Fluid Dynamics Conference and Exhibit, AIAA Paper 2001-3030, Anaheim, Calif, USA, 2001.
[18] I. Aya and H. Nariai, "Chugging Phenomenon Induced by Steam condensation into pool water (amplitude and frequency of fluid oscillation)," Heat Transfer-Japanese Research, vol. 14, no. 4, pp. 26-43, 1985.

[19] I. Aya, M. Kobayashi, and H. Nariai, "Pressure and fluid oscillations in vent system due to steam condensation (I) Experimental results and analysis model for chugging," Nuclear Science and Technology, vol. 17, no. 7, pp. 499-515, 1980. 


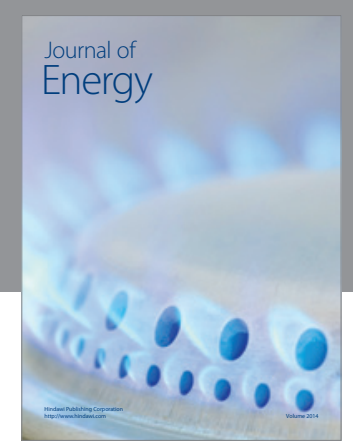

Journal of

Industrial Engineering
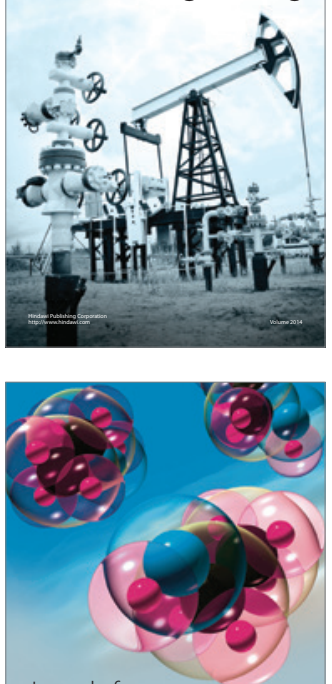

Fuels
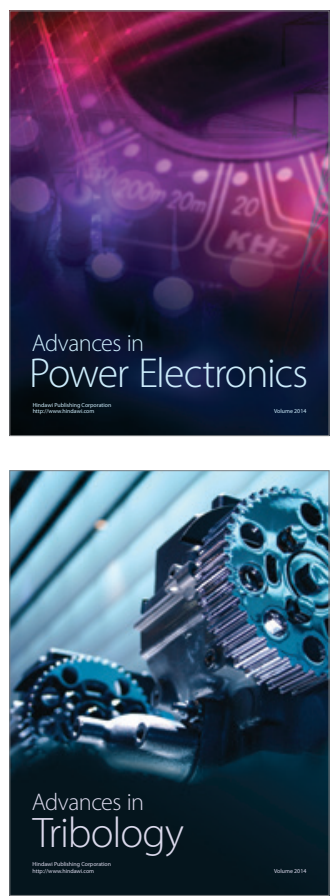

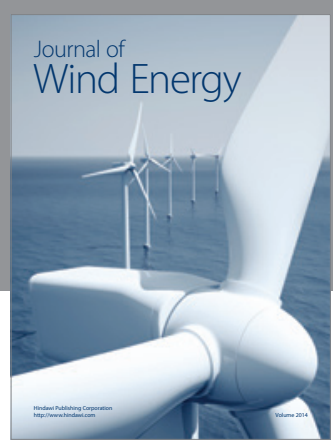

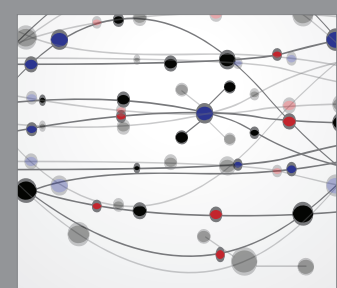

The Scientific World Journal

Submit your manuscripts at http://www.hindawi.com

Journal of

Structures
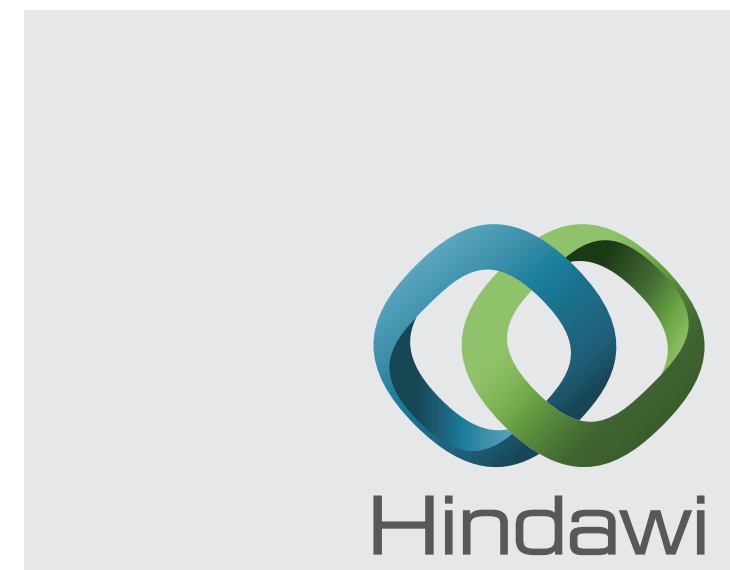

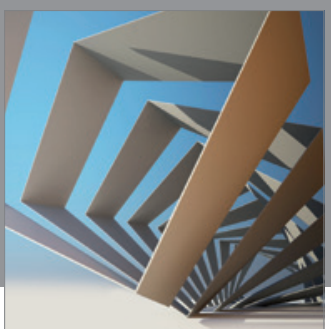

Rotating

Machinery
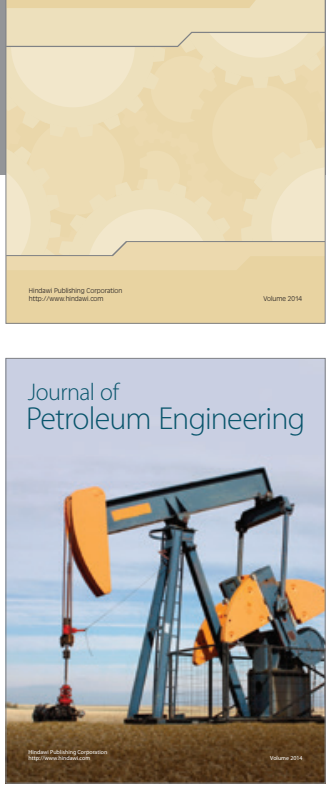

Journal of

Solar Energy
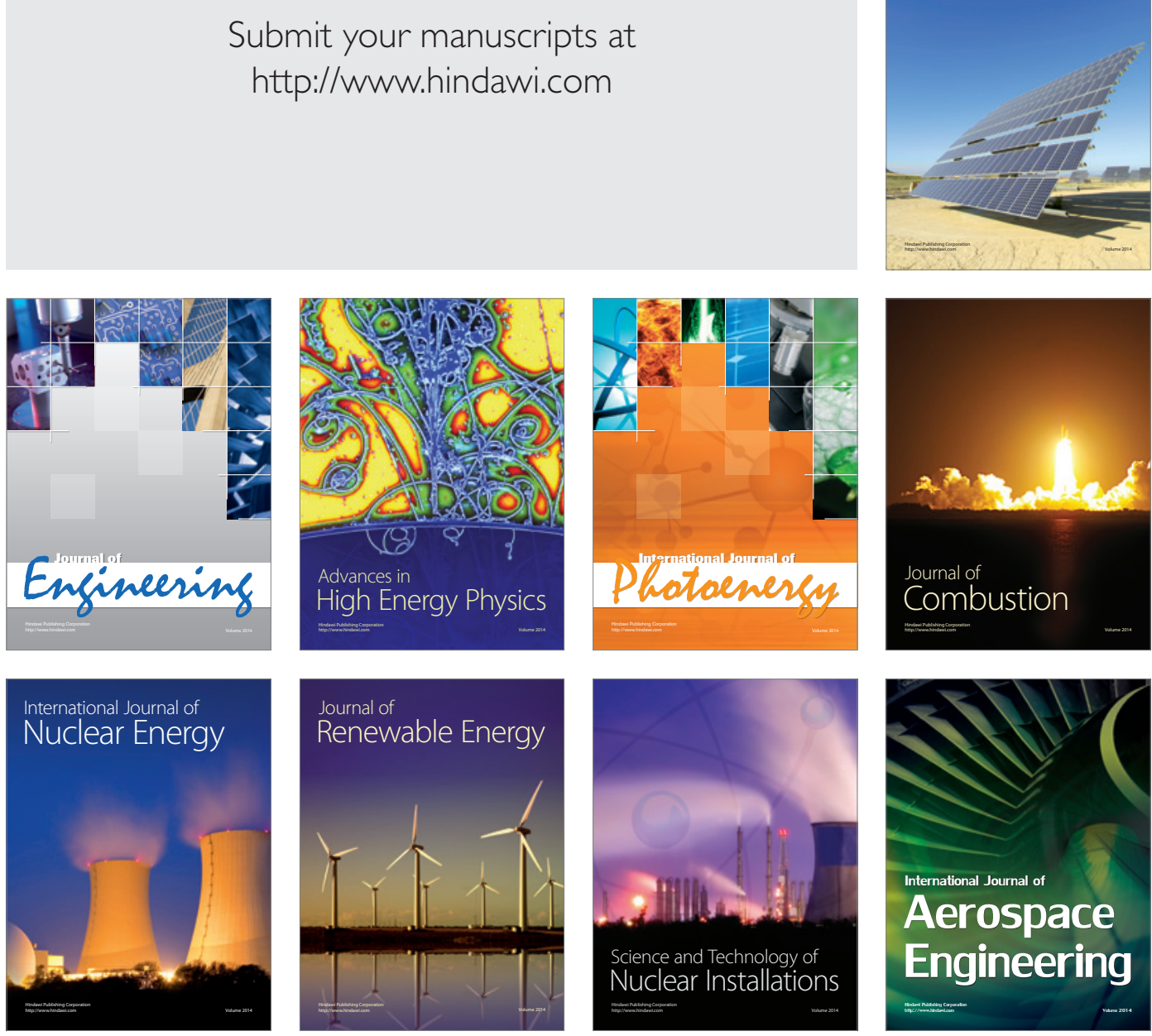